\title{
What characterizes planetary space weather?
}

\author{
Jean Lilensten • Andrew J. Coates • Véronique Dehant • \\ Thierry Dudok de Wit • Richard B. Horne • François Leblanc • \\ Janet Luhmann · Emma Woodfield • Mathieu Barthélemy
}

Received: 3 September 2014 / Published online: 12 November 2014

(C) The Author(s) 2014. This article is published with open access at Springerlink.com

\begin{abstract}
Space weather has become a mature discipline for the Earth space environment. With increasing efforts in space exploration, it is becoming more and more necessary to understand the space environments of bodies other than Earth. This is the background for an emerging aspect of the space weather discipline: planetary space weather. In this article, we explore what characterizes planetary space weather, using some examples throughout the solar system. We consider energy sources and timescales, the characteristics of solar system objects and interaction processes. We
\end{abstract}

J. Lilensten $(\varangle) \cdot$ M. Barthélémy Institut de Planétologie et d'Astrophysique de Grenoble (IPAG), Bâtiment D de physique, BP 53, 38041 Grenoble cedex 9, France e-mail: jean.lilensten@obs.ujf-grenoble.fr

\section{A. J. Coates $(\varangle)$}

Mullard Space Science Laboratory, University College London, Holmbury St Mary, Dorking, Surrey RH5 6NT, UK

e-mail: ajc@mssl.ucl.ac.uk; a.coates@ucl.ac.uk

V. Dehant

Solar-Terrestrial Centre of Excellence, Royal Observatory of Belgium, Avenue Circulaire 3, 1180 Brussels, Belgium

T. Dudok de Wit

LPC2E/OSUC, 3A avenue de la Recherche Scientifique, 45071 Orleans cedex 2, France

R. B. Horne · E. Woodfield

British Antarctic Survey, High Cross, Madingley Road, Cambridge CB3 0ET, UK

F. Leblanc

Laboratoire Atmospheres, Milieux, Observations Spatiales-CNRS/IPSL, Jussieu, Paris, France

J. Luhmann

Space Sciences Laboratory, University of California, Berkeley, CA, USA 
discuss several developments of space weather interactions including the effects on planetary radiation belts, atmospheric escape, habitability and effects on space systems. We discuss future considerations and conclude that planetary space weather will be of increasing importance for future planetary missions.

Keywords Space weather $\cdot$ Planets $\cdot$ Atmospheres

\section{Problematics}

Space weather is now an established discipline, at the interface between fundamental science and applications. In recent years, the phrase "Planetary space weather" has started to be used, with dedicated sessions at international meetings, and exciting perspectives for new interactions between disciplines such as planetology, heliospheric physics, and aeronomy. However, considerable ambiguity remains in such use. In this article, we address this simple question: What is planetary space weather? Is it the new name of planetary aeronomy? A new name for comparative planetology? Or does it have its own specific features?

Before answering these questions in detail, let us first examine the main properties of the solar system, with this topic in mind.

\section{The energy sources for planetary space weather}

The study of energy release from the Sun is a full discipline in itself. A recent review has been published that makes a full description of the different facets of the Sun that are relevant for terrestrial space weather (Zuccarello et al. 2013). In the following, we will briefly summarize the most important features.

\subsection{Solar spectrum}

Solar irradiance in the ultraviolet (UV, 120-400 nm), extreme ultraviolet (EUV, 10$120 \mathrm{~nm}$ ) and soft X-ray (XUV, 0.1-10 nm) bands is a key input to planetary space weather, as these energetic wavelengths are the main drivers of ionospheric and thermospheric variability (Lean 1997; Woods et al. 2004; Lilensten et al. 2008). Indeed, electromagnetic waves at these energetic wavelengths are the primary source of ionization on the dayside of planetary objects; sudden variations in their intensity, for example during solar flares, immediately impact ionospheric densities. They also affect the thermosphere, most notably through heating and expansion of the neutral atmosphere.

In comparison, solar radiation in the visible and near-infrared bands goes almost undisturbed through the atmosphere, and ends up heating the planetary surface or clouds directly. Details of these atmospheric absorption processes, however, are strongly planet dependent, because they are conditioned by atmospheric composition, pressure, etc.

The solar spectrum is known to closely follow Planck's law with an effective blackbody temperature of about 5,800 K. This spectrum peaks in the visible band, near 


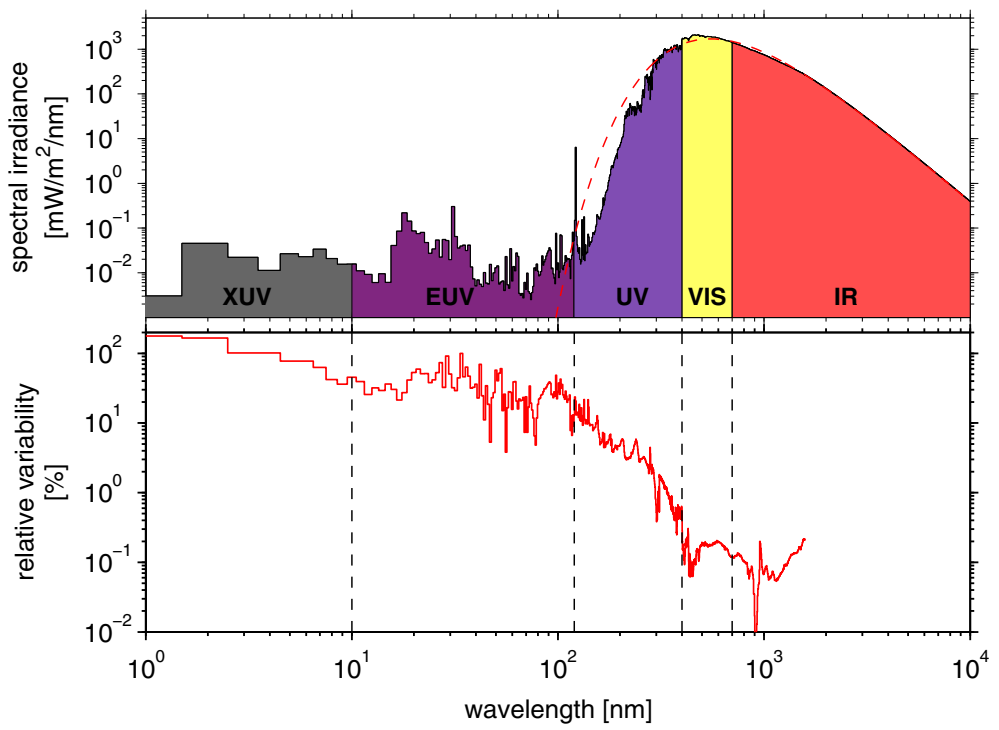

Fig. 1 Upper plot average value of the measured solar spectral irradiance, with Planck's black-body model for an effective temperature of 5,800 K (dashed). Bottom plot relative variability over an 11-year solar cycle. This plot is based on observations from the SORCE and TIMED spacecraft, running from 2003 till 2010

$460 \mathrm{~nm}$ (Fig. 1), and its intensity drops as expected as $R^{-2}$, where $R$ is the distance to the Sun. At the top of the Earth's atmosphere, the total solar irradiance, which is the integration of the solar spectrum over all wavelengths, is on average $1,360.8 \mathrm{~W} \mathrm{~m}^{-2}$ (Kopp and Lean 2011). The key properties of interest for space weather, however, are the variability of this spectrum and its associated atmospheric response. In the visible and infrared bands, which account for about $90 \%$ of the solar radiative output, the relative variability is extremely low, and rarely exceeds $0.1 \%$ over an 11 -year solar cycle (Lean 1997). Since most of this energy is absorbed at or near the surface, its impact on the planetary environment is weak, if not negligible. This is particularly true for planets such as Jupiter and the Earth, whose internal atmospheric variability largely exceeds that of solar forcing.

The remainder of the solar spectrum, i.e., the XUV to UV bands, is strongly enhanced with respect to Planck's black-body spectrum. Indeed, these bands predominantly consist of nonthermal emissions whose origin is rooted in the highly dynamic solar magnetic field, which is the source of all space weather events. This part of the spectrum is characterized by numerous spectral lines, among which the H I Lyman- $\alpha$ line at $121.5 \mathrm{~nm}$ is the most intense.

The relative variability of the spectral irradiance gradually increases from a few percent in the UV to exceed $100 \%$ in the XUV, for an 11-year solar cycle. For short transients such as flares, these figures can increase by an order of magnitude. Daily to weekly variations are dominated by the 27 -day rotation period of the Sun, and are driven by the appearance and disappearance of bright regions on the solar disk. Variations on timescales of years and beyond are dominated by the solar dynamo and its secular variations. 
A major issue with the solar spectral irradiance is its continuous monitoring with radiometrically accurate and inter-calibrated instruments. Measurements need to be made outside of the atmosphere to avoid absorption. The first direct measurements of the total solar irradiance started in the late 1970s, whereas the first continuous observation of the full solar spectrum, spanning from the XUV to the near-infrared, did not become available until 2003, with the launch of the SORCE satellite. For that reason, many models and most space weather users today still rely instead on solar proxies, which receive special attention in Sect. 8.2.

\subsection{Solar wind}

On average, the Sun loses about $3.6 \times 10^{12}$ protons $\mathrm{m}^{-2} \mathrm{~s}^{-1}$ (and about the same amount of electrons) as a "stellar wind"; the energy flux lost through this escape is $0.003 \mathrm{~W} \mathrm{~m}^{-2}$ (Phillips 1995). At $1 \mathrm{AU}$, this corresponds to a density of 5-6 protons and electrons $\mathrm{cm}^{-3}$. The mean velocity of this solar wind at $1 \mathrm{AU}$ is $372 \mathrm{~km} \mathrm{~s}^{-1}$ averaged over cycle 22 (Meyer-Vernet 2007). However, the variations of these characteristics are large. The fast solar wind is characterized by a velocity larger than $750 \mathrm{~km} \mathrm{~s}^{-1}$ and a density of 2.5 protons and electrons $\mathrm{cm}^{-3}$ at $1 \mathrm{AU}$. Occasionally, the velocity can reach more than $1,000 \mathrm{~km} \mathrm{~s}^{-1}$ while the density may decrease to less than 1 proton and electron $\mathrm{cm}^{-2} \mathrm{~s}^{-1}$ (see for example Hanlon et al. 2004a and references herein). On some occasions, the velocity increases while the density decreases. However, this is not a general feature since both can increase at the same time, especially during a long series of solar events (Miletsky et al. 2004; Richardson and Cane 2012a, b).

In the mean solar wind, the magnetic field strength at $1 \mathrm{AU}$ is of the order of $8 \mathrm{nT}$. During active events, it may reach values larger than $50 \mathrm{nT}$ (Miletsky et al. 2004). The direction of the magnetic field is usually in the well-established "Parker Spiral" (Parker 1958) orientation, determined by the solar rotation rate of the highly conducting, frozen-in solar wind plasma (about 27 days on average). In this configuration, the field lies near the ecliptic plane and points either toward or away from the Sun at a $45^{\circ}$ "Parker Spiral" angle with respect to the radial at Earth's orbit, with smaller angles at smaller heliocentric distances and larger angles beyond $1 \mathrm{AU}$. However, the interplanetary field can sometimes be highly variable, both during quiet and active conditions.

The two major types of solar wind disturbances related to the solar source are solar wind stream interactions, and coronal mass ejections (CMEs). The first of these are produced by the fact that the solar wind does not flow from the Sun with uniform properties, but rather as a collection of high- and low-speed streams from coronal holes and the coronal streamers, respectively. These different speed streams interact as they flow outward because the Sun is a rotating source. This makes "Parker Spiral" shaped compression regions where higher speed streams run into lower speed streams, and rarefactions where a low-speed stream follows a high-speed stream. The second of these, which can produce the most extreme solar wind and interplanetary field conditions, the CMEs, are produced by an eruption of plasma and field from the corona - the fastest and largest events of which are often related to flaring in an active region with strong magnetic fields on the solar surface (Sharma and Srivastava 
2012). These coronal "ejecta" can travel up to several thousands of $\mathrm{km} \mathrm{s}^{-1}$ through the ambient solar wind, causing the background plasma and field to pile up in front of it and creating a leading interplanetary shock. Such compressions produce the largest density and field compressions found in solar wind observations.

In orbit around Mercury, the NASA Messenger mission performed measurements close to the Sun. These data have been successfully modeled with the WSA-ENLIL MHD (Magneto-Hydro-Dynamics) simulation (Baker et al. 2013). The main results at Mercury's distance to the Sun are a mean magnetic field of $15 \mathrm{nT}$ (with a minimum around 8 and a maximum around 25), a velocity of about $450 \mathrm{~km} \mathrm{~s}^{-1}$ with a maximum value of $600 \mathrm{~km} \mathrm{~s}^{-1}$. The density is 40 protons and electrons $\mathrm{cm}^{-3}$, with values up to 80. In general, ballistic approximations are not adequate for extrapolating solar wind parameters from one heliocentric radius to another, because of the solar wind stream interactions and complications of CME propagation through the structured solar wind. The MHD models allow for better approximations of these evolutionary changes.

Further away from the Sun, the observations are from Cassini and other planetary missions to Mars, Jupiter or Saturn, but historically the behavior of the solar wind at large distances from the Sun was established by the Pioneer and Voyager missions. The evolution of the solar wind from 1 to $5 \mathrm{AU}$ is summarized in Hanlon et al. (2004a). At Jupiter's distance to the Sun, the magnetic field reaches lower values of $0.1 \mathrm{nT}$, with higher values of up to $4.3 \mathrm{nT}$ during active conditions. The velocity is close to that observed at $1 \mathrm{AU}$, ranging from 400 to $580 \mathrm{~km} \mathrm{~s}^{-1}$. The density is strongly reduced compared to that at $1 \mathrm{AU}$ : the minimum value reaches almost 0 with a maximum of $3 \mathrm{~cm}^{-3}$. There is a lack of continuous observations, however, and the values quoted here correspond to 10 days of observations during a flyby. Again, these values could be successfully compared with MHD modeling (Hanlon et al. 2004a). However, an additional complication that becomes important in the outer solar system solar wind is the presence of significant numbers of interstellar pickup ions. These change both the dynamics and composition of the solar wind and must be included at large distances, e.g., as we approach Pluto at $30 \mathrm{AU}$.

In December 2004, Voyager crossed the solar wind termination shock at $94 \mathrm{AU}$ from the Sun (Decker et al. 2005). Recently, it exited the solar system (Krimigis et al. 2011), revealed by a radial velocity of the solar wind equal to zero. This happened at a distance of $22 \mathrm{AU}$ from the termination shock at around $100 \mathrm{AU}$ to the Sun. Voyager is now observing the local interstellar medium. Over the previous 3 years, the velocity has been decreasing from $70 \mathrm{~km} \mathrm{~s}^{-1}$ down to zero, a value that remained constant after a while.

2.3 Galactic cosmic rays, solar energetic particle events, and interaction with the solar wind

The term cosmic rays refers to particles with kinetic energy that can be about the same order of magnitude as their rest mass. In practice, most cosmic ray protons and ions have energies from a few $\mathrm{MeV}$ to a few hundred of $\mathrm{MeV}$, but energies in the $\mathrm{GeV}$ range are also observed. Electrons from $10 \mathrm{~s}$ of $\mathrm{keV}$ to $100 \mathrm{MeV}$ are also part of this population. A distinction between the cosmic rays coming from the Sun, i.e., the solar 
cosmic rays or solar energetic particles (SEPs), and those coming from the galaxy, the galactic cosmic ray (GCR), is usually made (Dorman 2009). In the following, we will not distinguish between SEPs, solar energetic particle events or high-energy protons.

The solar wind affects GCR spectra: the GCR are scattered by magnetic fluctuations embedded in the outward-flowing solar wind. Consequently, the GCR fluxes, at energies of up to a few $10 \mathrm{~s}$ of $\mathrm{MeV}$ are less intense during periods of high solar activity. Moreover, the further from the sun, the less intense this "modulation" effect. Studies of the effects of solar modulation on the GCRs have been carried out for several solar cycles while measurements by spacecraft at various heliocentric distance have verified the theoretical predictions of the modulation effects, e.g., Dorman (2009). The solar wind also affects SEP transport. To a first approximation SEPs travel along the Parker Spiral field lines connected to their source. Their source may be a flare or a CME fixed at the Sun, or a traveling interplanetary shock preceding a CME in the solar wind. The latter sources produce the longest duration (several days) and the most intense solar particle events. Because they precede the shock and CME arrival at a particular solar system location, they are sometimes used as space weather storm predictors. However, SEPs can be seen even without a CME passage if the observer is connected to a flare or to a remote interplanetary shock that does not pass through their location.

SEPs are characterized by the increase, over periods of minutes to days, of the flux of protons, alpha particles, and minor amounts of heavier ions in the Mev range, as well as energetic (from 100s of keV to 10s of MeV) electrons (Mishev et al. 2011; Fino et al. 2014; Berrilli et al. 2014). Exceptional SEP events are sometimes detected by neutron monitors on the ground. At Earth, the subsequent increase of ionizing radiations at aircraft altitude, and in the space station, raises concern for human safety and leads to monitoring efforts (Mertens et al. 2010). SEPs also affect Earth's upper atmosphere chemistry, producing NO that leads to ozone depletions at high latitudes (Jackman et al. 2005a, b; López-Puertas et al. 2005; Rohen et al. 2005). The effect of SEP events has been also observed at Mars (Zeitlin et al. 2004), but their description at other bodies than the Earth still mainly relies on numerical simulations (Sheel et al. 2012).

\section{Characteristics of the different bodies on which the solar wind is acting}

Planetary bodies can be classified in different categories when considering the ways they interact with their solar environment. The existence or the lack of a global magnetic field is the very first element to consider. Its interaction with the solar wind will shape many characteristics of the electromagnetic environment of these bodies. In the same way, part of the energy and mass of the solar wind might interact directly with the planetary body atmosphere or surface. The presence or absence of a thick enough atmosphere will, therefore, be a key for the way a planetary body might react to the solar wind (see Sect. 6.1).

Tables 1 and 2 display only the planetary parameters that are relevant to the topic of this article, Table 2 focuses more on the solar wind and interplanetary magnetic field properties at the body. Many references may be consulted. Here, we give a short list of recommended sources (Schunk and Nagy 2000; Bauer and Lammer 2004; Sanchez- 
Table 1 Main characteristics of some solar system bodies related to planetary space weather

\begin{tabular}{|c|c|c|c|c|}
\hline Body & Atmosphere composition & $\mathrm{B}$ & $\mathrm{h} \nu$ arrival & Mean TSI \\
\hline Mercury & $\mathrm{Na}$ & Dipole & $3 \min 13 \mathrm{~s}$ & 9,040 \\
\hline Venus & $\mathrm{CO}_{2}, \mathrm{~N}_{2}, \mathrm{O}, \mathrm{CO}$ & - & $6 \mathrm{~min}$ & 2,620 \\
\hline Earth & $\mathrm{N}_{2}, \mathrm{O}_{2}, \mathrm{O}$ & Dipole & $8 \min 18 \mathrm{~s}$ & 1360.8 \\
\hline Mars & $\mathrm{CO}_{2}, \mathrm{CO}, \mathrm{O}$ & Crustal fields & $12 \min 39 \mathrm{~s}$ & 590 \\
\hline Jupiter & $\mathrm{H}_{2}, \mathrm{H}$, hydrocarbons & Dipole & $43 \min 14 \mathrm{~s}$ & 50.6 \\
\hline Saturn & $\mathrm{H}_{2}, \mathrm{H}$, hydrocarbons & Dipole & $1 \mathrm{~h} 19 \min 15 \mathrm{~s}$ & 15.1 \\
\hline Uranus & $\mathrm{H}_{2}, \mathrm{H}, \mathrm{CH}_{4}$ & Multipole & $2 \mathrm{~h} 39 \min 29 \mathrm{~s}$ & 3.72 \\
\hline Neptune & $\mathrm{H}_{2}, \mathrm{H}, \mathrm{CH}_{4}$ & Dipole & $4 \mathrm{~h} 9 \min 54 \mathrm{~s}$ & 1.52 \\
\hline Pluto & - & - & $5 \mathrm{~h} 28 \min 7 \mathrm{~s}$ & 0.9 \\
\hline Moon & - & Crustal fields + Earth's & $8 \min 18 s$ & 1,362 \\
\hline Io & $\mathrm{SO}_{2}, \mathrm{SO}, \mathrm{S}, \mathrm{O}, \mathrm{Na}, \mathrm{Cl}$ & Intrinsic + Jupiter's & $43 \min 14 \mathrm{~s}$ & 50.6 \\
\hline Europa & $\mathrm{O}_{2}, \mathrm{O}_{3}, \mathrm{O}, \mathrm{Na}$ & Induced + Jupiter's & $43 \min 14 \mathrm{~s}$ & 50.6 \\
\hline Ganymede & $\mathrm{O}_{2}, \mathrm{O}_{3}, \mathrm{O}$ & Intrinsic, induced + Jupiter's & $43 \min 14 \mathrm{~s}$ & 50.6 \\
\hline Titan & $\mathrm{N}_{2}, \mathrm{CH}_{4}$, hydrocarbons & Saturn's & $1 \mathrm{~h} 19 \min 15 \mathrm{~s}$ & 15.1 \\
\hline Saturn rings & $\mathrm{O}_{2}, \mathrm{O}, \mathrm{H}_{2} \mathrm{O}$ & Saturn's & $1 \mathrm{~h} 19 \min 15 \mathrm{~s}$ & 15.1 \\
\hline Comets & $\mathrm{H}_{2} \mathrm{O}, \mathrm{CO}, \mathrm{CO}_{2}$ & - & Variable & Variable \\
\hline Asteroids & - & -, Vesta crustal fields & Variable & Variable \\
\hline
\end{tabular}

Column 2: composition of the atmosphere (if existing) including that of the thermosphere. Column 3: magnetic field structure. Column 4: time that solar radiation needs to reach the body (rather than the distance to the Sun). The fifth column provides the total solar irradiance (TSI) in $\mathrm{W} \mathrm{m}^{-2}$. Note that, the atmosphere of Mercury is actually a surface-bounded exosphere

Table 2 Main characteristics of the interplanetary magnetic field (columns 2 and 3) and of the solar wind (columns 4 and 5) approaching different solar system objects

\begin{tabular}{lcllc}
\hline Body & Bimf $(\mathrm{nT})$ & Bimf angle $\left(^{\circ}\right)$ & $\begin{array}{l}\text { Solar wind density } \\
\left(\mathrm{cm}^{-3}\right)\end{array}$ & $\begin{array}{l}\text { Solar wind arrival } \\
(\text { days })\end{array}$ \\
\hline Mercury & 35.78 & 21.1 & 46.739 & 1.7 \\
Venus & 11.79 & 35.8 & 13.391 & 3.1 \\
Earth & 7.06 & 44.9 & 7.000 & 4.3 \\
Mars & 3.91 & 56.7 & 3.014 & 6.6 \\
Jupiter & 0.97 & 79.1 & 0.259 & 22.6 \\
Saturn & 0.52 & 84.0 & 0.077 & 41.4 \\
Uranus & 0.26 & 87.0 & 0.019 & 83.3 \\
Neptune & 0.17 & 88.1 & 0.008 & 130.5 \\
Pluto & 0.13 & 88.5 & 0.005 & 171.2 \\
Moon & 7.06 & 44.9 & 7.000 & 4.3 \\
\hline
\end{tabular}

The time in column 4 is in Earth days assuming a solar wind speed of $400 \mathrm{~km} \mathrm{~s}^{-1}$

Lavega 2011; Mendillo et al. 2011; de Pater and Lissauer 2010; Kivelson and Russel 1995; Lilensten and Blelly 2000) and a series of review articles (Coustenis et al. 2005, 2006, 2008a, b, 2009, 2010, 2012, 2013a,b). 
Table 3 Main magnetic field characteristics of some solar system bodies

\begin{tabular}{lcccc}
\hline Body & B inclination $\left(^{\circ}\right)$ & Intensity $(\mathrm{nT})$ & Orbital tilt $\left(^{\circ}\right)$ & Solar wind angle $\left(^{\circ}\right)$ \\
\hline Mercury & 14 & 300 & 7 & 90 \\
Earth & 10.8 & 31,000 & 23.4 & $67-114$ \\
Jupiter & -9.6 & 428,000 & 3.08 & $87-93$ \\
Saturn & 0.0 & 22,000 & 26.7 & $64-117$ \\
Uranus & -58.6 & 23,000 & 97.9 & $8-177$ \\
Neptune & -46.8 & 13,000 & 29.6 & $60-120$
\end{tabular}

The second column provides the inclination of the magnetic field compared to the rotation axis. The third column provides the intensity at the surface of the planet at the magnetic equator in nT. The fourth column gives the inclination of the rotation axis on the Ecliptic plane, or obliquity. The fifth column provides the range of angles between the radial direction from the Sun and the planet's rotation axis over an orbital period

Table 4 Some magnetosphere characteristics for different bodies of the solar system

\begin{tabular}{lll}
\hline Body & Subsolar point & Magnetosphere width \\
\hline Mercury & 1.5 & 1.4 \\
Earth & 10 & $8-12$ \\
Jupiter & 42 & $50-100$ \\
Saturn & 19 & $16-22$ \\
Uranus & 25 & 18 \\
Neptune & 24 & $23-26$ \\
\hline
\end{tabular}

In Table 3, we provide some characteristics related to the magnetic field of the planets. Here again, the diversity is large, the magnetic inclination may be nearly zero (Saturn) or large (Uranus). The planet's magnetic axis may be close to perpendicular to the Ecliptic plane (Jupiter), moderately inclined (Earth, Mercury) or close to the plane itself (Uranus, Neptune). The interaction between the induced magnetospheres and the solar wind will, therefore, be different.

Some characteristics of the solar wind interactions with the bodies of the solar system may immediately be deduced from this brief introduction. The first is that different bodies have different spatial scales and timescales for interacting with the solar wind. For example, the presence of planetary magnetic fields of different amplitudes will create different sizes of magnetospheres which are summarized in Table 4. Satellites can be submerged in their parent's body magnetosphere either permanently (e.g., Ganymede), or most of the time (e.g., Titan), or for a fraction of their orbit (e.g., Moon). The second characteristics is, therefore, the large variety of cases. Planetary bodies with and without magnetic fields interact with the solar wind and its field in different ways. The sizes of planetary magnetospheres and solar wind interaction regions differ significantly. The sizes depend on the nature of the object and its interaction, and specifically on whether the object is magnetized or unmagnetized. This is shown in Table 4 and illustrated in Fig. 2.

This makes it difficult to adopt a "general approach" to the topic of planetary space weather and we prefer, therefore, a "body-specific approach". Another alternative way 


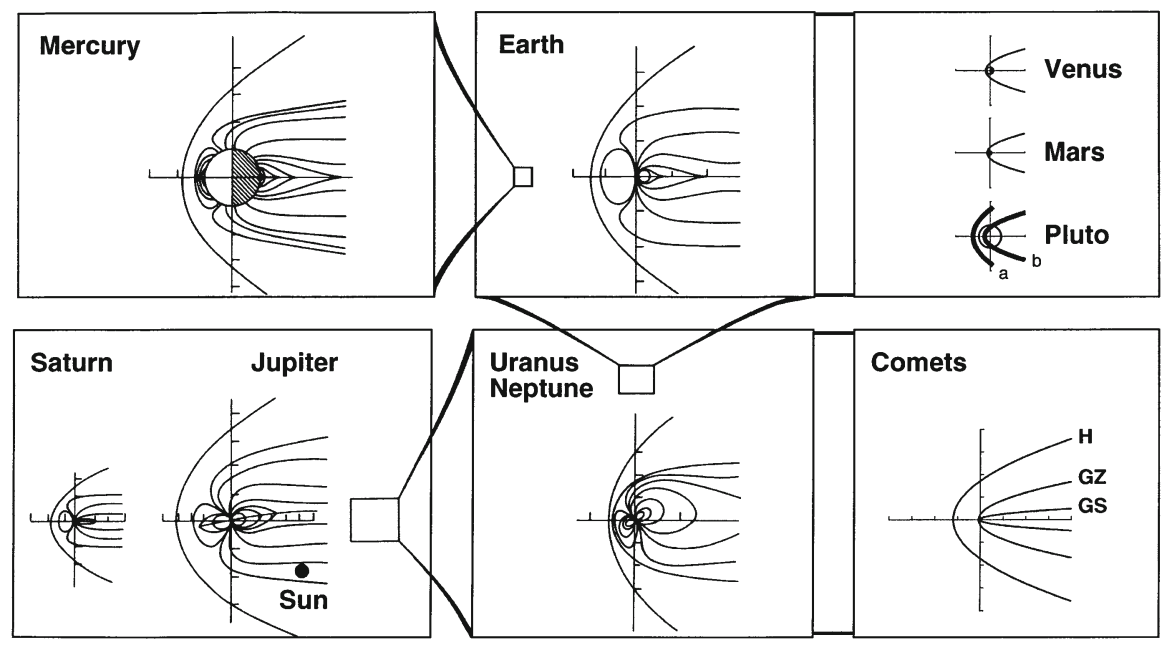

Fig. 2 Comparison of the sizes of magnetospheres and non-magnetic interactions with the solar wind (adapted by Coates 1999, 2001, from Kivelson and Russel 1995). The two panels on the right illustrate the bow shocks of non-magnetic objects. In the Pluto panel, Charons orbit is shown as a circle, and the anticipated shock locations are shown when Pluto is closest to the Sun (a) and furthest from the Sun (b), so that the atmosphere is more tenuous. Bow-shock locations of the three comets visited by spacecraft with suitable instrumentation prior to Rosetta are shown as $H$ (Halley, Giotto), GZ (GiacobiniZinner, ICE) and GS (GriggSkjellerup, Giotto). The comet Borrelly bow-shock location was similar to that of GZ

Table 5 In a process point of view for characterizing the effects of the solar emissions and winds on different bodies, we consider the existence of ionosphere (I), magnetosphere (M), or atmospheric escape (E)

\begin{tabular}{ll}
\hline Body & Effects \\
\hline Mercury & E \\
Venus & I, E \\
Earth & I, M, E \\
Mars & I, E \\
Jupiter & I, M \\
Saturn & I, M \\
Uranus & I, M \\
Neptune & I, M \\
Pluto & E \\
Moon & - \\
Io & E,Torus \\
Europa & I, E \\
Ganymede & I, M, E \\
Saturn rings & I, E \\
Titan & I, E \\
Enceladus & I, E \\
Comets & E \\
\hline
\end{tabular}

of overcoming the lack of generalization is to consider a "process-based point of view", which describes the phenomena. In the frame of this work, the effective features to 
consider are the generation of an intrinsic or induced magnetosphere, an ionosphere, a thermosphere, atmospheric escape, and in some cases the production of planetary ions and neutral torus. Table 5 summarizes the existence of magnetosphere, ionosphere, or atmospheric escape for different bodies of the solar system.

\section{Different processes and features for the different solar system bodies}

\subsection{Radiation belts}

Earth's radiation belts are a well-known aspect of terrestrial space weather for the dangerous environment they pose for satellites and astronauts (Horne et al. 2013; Gubby 2002). The major space weather hazard for satellites above low Earth orbit is from very high-energy particles (such as cosmic rays and solar energetic particles) or from the slightly less high-energy particles in the radiation belts, which can cause both internal and surface charging problems leading to electrostatic discharge (e.g., Hastings and Garrett 1996). At the Earth, the high-energy particle populations that are trapped within the radiation belts can increase rapidly during geomagnetic storms from which they can take a long time to decay.

Jupiter, Saturn, Uranus and Neptune also have established radiation belts (Mauk and Fox 2010 and references therein) with Jupiter being the most intense example in the solar system with ultra-relativistic electrons of $50 \mathrm{MeV}$ or more at 1.5 Jovian radii $\left(\mathrm{R}_{J}\right)$ (Bolton et al. 2002; de Pater and Dunn 2003). However, the different physical parameters and dynamics of these magnetospheres compared to those of Earth imply that the generation and behavior of radiation belts must be considered individually at each planet.

At the Earth, the primary mechanisms responsible for the dynamics of the radiation belts are radial diffusion [radial transport and acceleration or loss caused by breaking of the third adiabatic invariant (Walt 2005)] and acceleration and loss processes due to resonant interactions with various waves present in the magnetosphere. The radial diffusion at the Earth is a result of both electromagnetic and electrostatic variations, the former due to ULF waves and the latter due to convection electric field fluctuations (for example from substorm processes).

Radial diffusion and local acceleration and loss processes also drive the dynamics at the other planets; however, in contrast to the Earth the radial diffusion is driven by ionospheric winds as originally suggested for Jupiter by Brice (1973). The ionospheric winds mechanism also gives the best fit to radial diffusion rates at Saturn (Hood 1983), Neptune (Selesnick and Stone 1994) and Uranus (Selesnick and Stone 1991). The origin of the ionospheric wind variations lies in solar heating of the planet's atmosphere which means that variations in solar UV/EUV output should affect the rate of radial diffusion. Indeed, variations with solar output have been found at Jupiter (Kita et al. 2013) and at Saturn (Krupp et al. 2014).

It is also very important to consider additional major loss processes in the radiation belts of the outer planets that do not exist at the Earth, primarily due to absorption of energetic particles by moons, rings and dust, but also for example energy losses due to synchrotron radiation which is particularly important at Jupiter. At Saturn for 


\begin{tabular}{|c|c|c|c|c|}
\hline $\begin{array}{l}\text { Table } 6 \text { Radiation belts main } \\
\text { characteristics (adapted from } \\
\text { Mauk and Fox 2010) }\end{array}$ & Body & $\begin{array}{l}\text { Radiation } \\
\text { belts }\end{array}$ & $\begin{array}{l}\text { Internal } \\
\text { sources }\end{array}$ & $\begin{array}{l}\text { Magnetosphere } \\
\text { size } R_{\text {body }} / \mathrm{km}\end{array}$ \\
\hline & Mercury & No & Ionosphere & $1.4 / 3.6 \times 10^{3}$ \\
\hline & Earth & Yes & $\begin{array}{l}\text { Ionosphere, } \\
\text { Moon (when in } \\
\text { tail) }\end{array}$ & $8-12 / 7 \times 10^{4}$ \\
\hline & Jupiter & Yes & $\begin{array}{l}\text { Ionosphere, } \\
\text { Io + other moons }\end{array}$ & $50-100 / 7 \times 10^{6}$ \\
\hline & Saturn & Yes & $\begin{array}{l}\text { Ionosphere } \\
\text { Enceladus, Titan, } \\
\text { other moons }\end{array}$ & $16-22 / 1 \times 10^{6}$ \\
\hline & Uranus & Yes & Ionosphere & $18 / 5 \times 10^{5}$ \\
\hline & Neptune & Yes & Ionosphere & $23-26 / 6 \times 10^{5}$ \\
\hline
\end{tabular}

example, the moons cause distinct gaps in the radiation belts where all the particles are absorbed (e.g., Roussos et al. 2008). The offset of the magnetic and rotational axes at Jupiter (by approx $10^{\circ}$ ) means that energetic particles bouncing north and south through the magnetic mirroring close to the equator, with pitch angles greater than $70^{\circ}$, can pass by the moons much more easily (Santos-Costa and Bourdarie 2001). The offset of the magnetic axis as Saturn is close to zero, so virtually all of the energetic particles are absorbed. It is also important to consider the character of the moon itself: is it an absorbing body or does it have sufficient magnetic properties to deflect the plasma flow around it? For a good summary on plasma flow around moons the reader is referred to chapter 21 in Bagenal et al. (2004) (Table 6).

Local acceleration and loss due to wave particle interactions have been studied in depth at the Earth (Horne et al. 2005). Many of the wave types observed at the Earth have also been observed at other planets (e.g., Kurth 1992; Menietti et al. 2012) and have the potential to cause local acceleration or losses. As well as the strength of the waves, an important ratio affecting the local acceleration by waves is that of the plasma frequency to the gyrofrequency (which is a ratio characterizing the relative cold plasma density to the magnetic field strength). For local acceleration to be effective, then this ratio should be less than approximately 4 (Horne et al. 2005) and a comparison of conditions at Jupiter, Saturn and the Earth shows that they are most favorable at Jupiter (Shprits et al. 2012). Indeed, studies have found that acceleration due to cyclotron resonant interactions between electrons and whistler-mode chorus waves at Jupiter is strong (Horne et al. 2008) and plays a major role in creating the radiation belt outside of the moon Io (Woodfield et al. 2014).

Understanding the origin and dynamics of these high-energy particle environments is crucial for the planning and operation of current and future space missions to the planets. Modeling of radiation belts at the outer planets has until very recently included only the radial diffusion of electrons [at Jupiter (Goertz et al. 1979; Santos-Costa and Bourdarie 2001; Sicard and Bourdarie 2004) and at Saturn (Hood 1983; SantosCosta et al. 2003)]. More recently, local acceleration processes due to wave particle 
interactions have also been included in addition to radial diffusion in the modeling process; at Jupiter (Woodfield et al. 2014) and at Saturn (Lorenzato et al. 2012).

\subsection{Magnetosphere}

For those planets which possess a well-structured magnetosphere (Mercury, Earth, Jupiter, Saturn, Uranus and Neptune) there are three main drivers of the dynamics, the solar wind, the planetary magnetic field, and the planetary rotation. Which driver dominates depends on the characteristics of the planet considered; for example, at Jupiter, the combination of a very strong magnetic field and a rapid planetary rotation dominates the changes in the magnetosphere rather than the effects of the solar wind. Whereas, at the Earth, the energy input from the solar wind to the classic Dungey open magnetosphere (Dungey 1962) is very much dominant over the planetary rotation.

For the moons of planetary bodies, we should take into consideration that they can either permanently, most of the time, or for a fraction of their orbit be submerged in their parent body's magnetosphere. Some satellites even possess their own magnetic field which interacts with the parent's one [e.g., Europa has an induced magnetic field (Kivelson et al. 2000), Ganymede has an intrinsic magnetic field (Kivelson et al. 2002)].

Addressing the planetary environments, therefore, poses new problems that will need to be solved for predicting the environments which space missions-possibly manned-will have to face during extreme space weather events.

\subsection{Heating and cooling processes in the upper thermosphere}

The main heating sources of the terrestrial planetary upper atmospheres are the absorption of the solar UV flux and the consequent impact of the solar wind (Fox et al. 2008; Wedlund et al. 2011; Kutiev et al. 2013). This energy is transported by heat conduction to lower layers of the thermosphere where energy can be radiated locally by infrared active molecules such as $\mathrm{CO}_{2}$ (González-Galindo et al. 2009) contributing to the cooling of the atmosphere. While the UV solar photons mainly heat the upper thermosphere, the IR solar photons can also heat the lower regions of the thermosphere. For example, on Mars and Venus, IR heating is the dominant heating process in the regions below the ionospheric peak, and this controls the altitude of the peak.

\subsection{Chemistry of the upper thermospheres}

Chemical reactions play a fundamental role in the planetary upper atmospheres. Solar photons can initiate complex chemical cycles through dissociation, ionization, or excitation of the main neutral species. The light species which become dominant in terrestrial planetary upper atmospheres are produced through dissociation of the main species. For example atomic oxygen on Venus and Mars results from the photodissociation of $\mathrm{CO}_{2}$, while on the Earth it results from photodissociation of $\mathrm{O}_{2}$. Atomic hydrogen in terrestrial planets is produced by photodissociation of water vapor. 
The chemistry of the Earth's upper atmosphere is relatively simple compared to that of other bodies and even if it includes both ion-neutral and neutral-neutral reactions, a series of less than 20 reactions is enough for most of the space weather purposes (Danilov 1994; Rees 1989). The cases of Venus and Mars are still of relatively simple approach (e.g., Bougher and Borucki 1994). The picture is very different as soon as carbon atoms can react with hydrogen, both coming from the dissociation of different molecules. The case of Titan, where methane and carbon dioxide co-exist in large quantities reveals a very complex chemistry with about a thousand of each type of reactions (Dutuit et al. 2013). This complexity makes it impossible (with current computer facilities) to include a detailed chemical description of the atmosphere in a global atmospheric model solving also the production through photo-absorption or electron impacts and the time-dependent continuity equation. Since both production sources depend on solar activity, the chemistry of the upper atmosphere of such complex bodies as Titan will remain difficult to understand for several years.

\subsection{Upper neutral atmospheres: thermosphere and exosphere}

One of the important aspects of planetary space weather concerns the interaction of the upper atmospheres with solar wind particles and fields. Before considering these effects, however, it is useful to have an idea of the nature of these upper atmospheres in the absence of solar wind, in particular at altitudes where sunlight exposure and solar rotation mainly control their behavior. Above the "homopause", where the atmospheric gases are well mixed, the planet's gravity leads to diffusive separation of species by mass. The baseline atmosphere is then controlled by the combination of solar heating, atmospheric composition-specific cooling mechanisms, and planetary rotation rate. As usual, the average velocity of a molecule is determined by temperature, but the velocity of individual molecules varies continuously as they collide with one another, gaining and losing kinetic energy. At some higher level, the atmospheric gases cease to collide with one another while still being heated by the Sun. The altitude where the mean free path equals the scale height is the exobase. Above this altitude (in the exosphere), the pressure force does not play any role because of rare collisions. The particles reaching this altitude have a probability to escape equal to 1/e (Chamberlain 1964).

The few particles that have enough energy to reach above this exobase can either be on ballistic or satellite orbits around the planet, or, if they have outward velocities above the escape velocity for the planet, can be lost to space. This thermal or "Jeans" escape (related to collisions) (Selsis 2005) affects mostly the lightest species, such as Hydrogen. Under some circumstances of intense heating the exobase can approach the collisional region and a "hydrodynamic" type of atmosphere outflow can occur with heavier elements dragged along with the escaping hydrogen.

The atmospheres of the Moon and Mercury are usually described as surfacebounded exospheres (Stern 1999) because their exobase is below their surface. In that case, their atmosphere is produced from particles ejected from the surface by several processes (thermal release, sputtering, chemical reaction, meteoritic impact or interior outgassing) (Stern 1999). The importance of each source and loss term 
depends on the species considered, and is still poorly known (see the reviews by Stern 1999 and Leblanc et al. 2007 for more detailed descriptions of the exospheres of atmosphere-less bodies such as the Moon and Mercury).

Because the vertical gradients are stronger than the horizontal ones, most thermospheric models separate the horizontal and vertical dynamics (e.g., Dickinson and Ridley 1975 or Schubert et al. 1980). In most global planetary models, the pressure gradient in the vertical direction is balanced by the gravity force (Bougher et al. 2008). This hydrostatic assumption is correct only for small vertical velocities such as in the current terrestrial planets of the solar system, but fails to simulate the putative hydrodynamic phase of terrestrial planets (Chassefière and Leblanc 2004) or exoplanets undergoing hydrodynamic escape (Vidal-Madjar et al. 2004). This is why some models incorporate non-hydrostatic equations (Ridley et al. 2006; Deng et al. 2008).

In the thermosphere, the diffusion becomes the dominant vertical process and can be solved for each species, knowing the diffusion coefficients in the mixed gas forming the atmosphere. For 1D models, an empirical mixing coefficient $K$ representing both eddy mixing and mixing due to large scale winds is parameterized (Krasnopolsky 2002). Three-dimensional models of upper atmospheres of planets, which incorporate latitudinal and day-night gradients as well as atmospheric chemistry, have become more common in general (e.g., Bougher et al. 2009).

\subsection{Ionospheric structure and dynamics}

Planetary ionospheres are produced mainly by sunlight incident on the neutral upper atmospheres. The light photoionizes the neutrals, producing photoelectrons and ions that unlike the neutrals respond to local electric and magnetic fields, as well as gravity, collisions and pressure gradients. The dynamics of the ions and electrons is more complicated than the neutral dynamics due to both the feedback processes between plasma and electromagnetic fields, as well as the collisional interactions with neutrals and photochemistry. The complete and simplified equations of the ion dynamics can be found in Schunk and Nagy (2000) and Lilensten and Blelly (2000). For gas giants, the ionospheric dynamics and its interaction with the neutral atmosphere could play an important role in the dynamics and heating of the neutral atmosphere (Bougher et al. 2009). For terrestrial planets, the dynamics is important in the upper part of the ionosphere, above the main ionospheric peak and is enhanced in regions where space weather processes increase ionization or introduce magnetic and electric fields. As mentioned above, the photochemistry of ionospheres controls some properties of the neutral upper atmospheres, such as the creation of "hot" contributions to the exospheric density in the form of "coronal" contributions from dissociative recombinations of ionospheric ions.

\subsection{Effects of cosmic rays on planetary atmospheres}

The main effect of cosmic rays in a planetary atmosphere is the creation of an "air shower", i.e., a series of ionization and excitation/emission processes, leading to the creation of a low altitude ionosphere layer. In addition, these showers create emissions, 
typically of nitrogen lines for the Earth, that are observed from the ground (e.g., Auger observatory) (Velinov et al. 2013). Recently, observations of Titan during eclipse showed an emission between 300 and 1,000 km altitude. These emissions could be coming from chemiluminescence, or cosmic rays impacting the atmosphere (West et al. 2012).

Cosmic rays are at the core of a controversial hypothesis about Earth climate evolution (Engels and van Geel 2012; Laken et al. 2012). Several studies suggested that GCR play a role in aerosol creation and thus cloud formation, linking GCR fluxes to the climate (Svensmark et al. 2009; Enghoff et al. 2011; Dorman 2012), but the importance of these processes is highly debated (Erlykin et al. 2009, 2010; Laken and Calogovic 2013).

The relation between ionizing radiation and haze formation has been observed on giant planets such as Neptune (Romani et al. 1993). At Titan, a correlation between cosmic ray ionization altitudes and aerosol layers has been observed (Gronoff et al. 2009a, b, 2011).

\subsection{Airglow and aurorae}

In general, planetary upper atmospheres radiate or scatter solar UV, Visible and IR emissions. The atmospheric photoemissions of excited states of molecules and atoms are grouped under the generic name airglow which include aurorae, depending on the production mechanisms. The sources of airglow and aurora are excited states of atoms or molecules that de-excite to lower states.

Airglow includes dayglow when the main exciting species are UV photons, and nightglow. In nightglow, chemistry and/or transport of dayside-excited species to the nightside may be involved in the observed emissions (Simon et al. 2009). Auroral emissions constitute a very important feature in terrestrial space weather, and are an important part of planetary space weather as well. Aurorae come from the impact of energetic particles precipitating along magnetic field lines into the thermosphere. In the case of the Earth, these particles are essentially electrons and/or protons originating in the solar wind, and reaching the upper atmosphere after a series of accelerations. Aurorae can thus be considered as one aspect of planetary space weather. Depending on the planet or satellite, airglow and aurora involve principally $\mathrm{N}_{2}, \mathrm{O}_{2}, \mathrm{O}, \mathrm{CO}_{2}, \mathrm{CO}, \mathrm{NO}$, $\mathrm{OH}, \mathrm{H}, \mathrm{H}_{2}$ and their corresponding ions. The variety of emissions is, therefore, large. Visible emissions are relatively rare in the solar system. Atomic oxygen and molecular nitrogen are the main emitting species in this range (e.g., Rees 1974, 1989). The most intense auroras in the visible are found at Earth, but red emissions also occur at Venus and Mars (Gronoff et al. 2011). As far as giant planets are concerned, the emissions are mostly in the UV (Grodent 2014; Barthélemy et al. 2014) and in the IR ranges (Miller et al. 2006). In this later work, it is shown that $\mathrm{H}_{3}^{+}$molecular ion constitutes a good tracer of energy inputs into Jupiter, Saturn and Uranus and probes of physics and chemistry of the upper atmospheres of giant planets.

Describing this variety of emissions is a challenge for future efforts. It requires solving a stationary Boltzmann equation (Schunk and Nagy 2000) for which an important parameter is the collision cross-section. Electron impact cross-sections are quite well 
known. Many proton impact cross-sections are still missing and even at Earth, the proton aurorae have been difficult to model (Simon et al. 2007 and references therein). The multiplicity of cases in the solar system increases the need. As an example, the Io torus produces auroras that are due to heavy sulfur ions precipitating onto Jupiter. The impact cross-sections between these ions and the neutral jovian atmosphere are totally unknown.

\section{Defining space weather}

With the concepts and processes described in the previous sections, we can now address the topics of space weather. Two definitions are widely used. The first one is the US National Space Weather Plan definition:

Conditions on the Sun and in the solar wind, magnetosphere, ionosphere, and thermosphere that can influence the performance and reliability of space-borne and ground-based technological systems and can endanger human life or health.

This first definition restricts space weather to the Earth. Clearly another definition must be used that encompasses the planetary aspects.

The second widely used definition of Space Weather was adopted in 2008 by 24 countries and the European Space Agency (Lilensten and Belehaki 2011):

Space weather is the physical and phenomenological state of natural space environments. The associated discipline aims, through observation, monitoring, analysis and modeling, at understanding and predicting the state of the Sun, the interplanetary and planetary environments, and the solar and non-solar driven perturbations that affect them; and also at forecasting and nowcasting the possible impacts on biological and technological systems.

This definition includes the planets because it focuses on space environments. It explicitly states that planetary space weather cannot be disconnected from solar activity and covers several aspects:

- to understand the nature of planetary space environments,

- to forecast and nowcast. This is required where human impacts and technologies are present.

It also points towards impacts on biological and technological systems. In the following, we therefore adopt this second definition.

\section{Planetary space weather considerations}

Following this definition, the first objective behind planetary space weather clearly is a better understanding of planetary space environments. This aspect of planetology has long been termed space physics and aeronomy, and sometimes space aeronomy (Banks and Kockarts 1973). An important change occurred in the last 20 years, as we now have a much more detailed and dynamic picture of these environments. We know today that there are variations in the planetary space environments over all timescales, from minute-to-minute to evolutionary. These timescales are linked with the different variabilities of the Sun: active region development, solar rotation, solar 
cycle and longer term changes. Effects of interest range from auroral phenomena and their consequences, to magnetosphere and radiation belt variability, to atmosphere escape history.

Planetary Space weather thus focuses on the variability of the space environments at all timescales including space climate, related to solar variability.

We now understand that the "old" view of the solar system, which focuses on distinct objects, is best replaced with a broader perspective. To understand each of the planetary objects, we must consider their history under a changing Sun, and group them into common classes: rocky, gaseous, icy objects, dusty systems, magnetospheres and atmospheres. This "comparative planetology" view is timely and extremely valuable because it allows one to see how the various natural "experiments" that each planet provides are related, and how the different properties of planets cause them to respond differently to our Sun and its outputs. Indeed, the recent explosion in the detection and characterization of exoplanets, and its connections to our own solar system, makes planetary space weather a subject of expanding interest and importance.

In the following paragraph, we describe some examples of Planetary space weather phenomena. This list is of course not intended to be exhaustive, but rather to illustrate the breadth of the science involved.

\subsection{Some examples of the effect of the solar wind}

\subsubsection{Propagation of the solar wind in the solar system}

In the frame of this study, interplanetary propagation of particles from the Sun may be divided into two categories:

- Disturbed solar wind (energies of the order of $1 \mathrm{keV}$ ) propagation, including dynamic effects from CMEs and corotating interaction regions (CIRs),

- Solar energetic particle (energy E larger than $10 \mathrm{MeV}$ ) propagation (Vainio et al. 2013).

In addition to these rapidly changing populations in different energy ranges, with consequently different arrival times, galactic cosmic rays (GCRs, energy between $100 \mathrm{MeV}$ to $\mathrm{GeV}$ ) are also present throughout the heliosphere, with a morphology related to the solar cycle. SEPs and CGRs may provide single event upsets and effects in instrumentation (e.g., coronograph data on SOHO and STEREO, as well as plasma measurements on ACE, are both affected by penetrating SEPs).

The propagation of disturbed solar wind has been tracked in a number of studies (e.g., Prangé et al. 2004; Futaana et al. 2008; McKenna-Lawlor et al. 2008; Rouillard et al. 2009). The standard software to model the propagation of these disturbances is currently ENLIL (Baker et al. 2013). For magnetized objects in the inner solar system such as Mercury and Earth, this is routinely done and well tested. For the outer solar system magnetized planets Jupiter, Saturn, Uranus and Neptune, the errors are higher. At unmagnetized objects such as Venus and Mars in the inner solar system and comets at a range of distances, solar wind conditions can have a significant effect on plasma loss rate (e.g., Edberg et al. 2011; Hara et al. 2011). 
The outer planet satellites provide interesting examples in the outer solar system: magnetized Ganymede generates a magnetosphere within Jupiter's magnetosphere, while Io is a large unmagnetized source inside Jupiter's magnetosphere. Callisto, as well as Ganymede, has weak atmospheres. At Saturn, Titan has a substantial atmosphere that is usually immersed in Saturn's magnetosphere, and loss rates have been estimated (e.g., Coates et al. 2012). However, Cassini has also measured examples with Titan in Saturn's magnetosheath and in the solar wind.

SEPs may also be tracked between planets by measuring the onset of penetrating, or directly measured energetic, particles (e.g., Futaana et al. 2008; Rouillard et al. 2011).

\subsubsection{Control of the atmosphere by the solar wind}

Besides shaping the electromagnetic environment of the planetary objects in the solar system (Sect. 4.1), the solar wind can have a significant impact on their atmosphere. This is particularly true in the case of a weakly magnetized objects like Mercury, Venus, Mars and our Moon. To describe these effects, we need to distinguish planetary objects having a thick atmosphere from those without. By thick atmosphere, we mean an atmosphere dense enough to stop most of the solar particles impacting it.

Clearly, this is not the case of Mercury, which can be classified as a planet with a weak magnetic field (1-2 orders weaker than the one of the Earth, see Table 3) and no atmosphere (Mercury's atmosphere is in reality an exosphere; see Table 1 and Sect. 4.5). It is thanks to this weak magnetic field that, in the early $80 \mathrm{~s}$, the signatures of the interaction between Mercury's surface and the incident solar wind could be observed (Potter and Morgan 1990). Potter and Morgan provided the first image of Mercury's sodium atmosphere and observed high latitude peaks that they associated with the interaction of the solar wind with Mercury's surface. Indeed, in an analogy with Earth's magnetosphere, these peaks were interpreted as Mercury's intrinsic magnetic field organizing solar wind penetration via a cusp-like structure at high latitudes. When impacting the surface, the solar wind particles would then sputter the surface (Johnson 1990). We now know that Mercury's magnetosphere is significantly different from the Earth's and that this analogy is somewhat limited (Anderson et al. 2011). But many observations of Mercury's sodium exosphere have been made during the last 30 years, all concluding that the only plausible explanation of these features is related to the interaction of the solar wind with Mercury's magnetosphere (Leblanc et al. 2009). One open issue remains the relation between the impact of solar wind particles with Mercury's surface and the production of the observed local peak of sodium density. Indeed, energetic solar wind particles can either directly sputter the surface or induce the diffusion of the sodium atoms trapped in the regolith which could be later ejected (Mura et al. 2009). A similar process has been identified at the Moon (Wilson et al. 2006). It is, therefore, largely accepted that solar wind sputtering should play an important role for the production of some of the species present in Mercury's environment. But the interaction of the solar wind does not only produce a local atmosphere. The recent set of missions around the Moon highlighted several new features induced by the solar wind interaction with a surface. As an example, Chandrayaan-1 highlighted for the first time the importance of neutral and ionized 
backscattered solar wind protons, up to $10 \%$ of the incident particles (Wieser et al. 2010). Pickup ions accelerated by the solar wind convection electric field have been observed in the Moon's tail (Mall et al. 1998) as well as in Mercury magnetospheric tail (Vervack et al. 2010). To briefly summarize, in the case of weakly magnetized object with limited atmosphere, the solar wind can interact directly with the surface and induce sputtering, accelerated planetary ions, backscattered energetic neutral particles and surface charging effects, and in the long term could erode the surface or enrich it in specific elements (Ozima et al. 2005). During solar energetic events, it is expected that this interaction is significantly enhanced leading to a much wider region impacted by solar wind particles at Mercury (Kallio and Janhunen 2003), increased ejection from the surface (Potter et al. 1999) and increased surface potential (Halekas et al. 2009).

A similar conclusion could be reached, to first order, in the case of weakly magnetized object with dense atmosphere. The main difference with the previous class of objects is that the solar wind will interact with an atmosphere and ionosphere rather than with a surface. As in the case of the solar wind interaction with the surface, the solar wind energy and momentum can be deposited inside the atmosphere leading to its erosion by sputtering (Wang et al. 2013), can pick up planetary ions, can lead to the production of neutral particles by charge exchange (Nilsson et al. 2010) and can also heat and ionize the atmosphere (Fang et al. 2013) or deposit matter (Chanteur et al. 2009). In the same way as for surface interacting with the solar wind, this interaction can lead to the ejection of matter above the atmosphere, populating the exosphere (Wang et al. 2013). In the case of Mars, this interaction could have led to a significant erosion of Mars' atmosphere during the early solar system (Chassefière et al. 2007) (see Sect. 6.2.2).

\subsubsection{Solar wind control of the magnetosphere: the example of Jupiter and Saturn}

The effect of the solar wind on the magnetospheres of Jupiter and Saturn appears to be more related to the presence of solar wind shocks and the consequent changes in magnetospheric size and not so much on the strength and direction of the IMF which does have a strong impact at the Earth. The magnetospheric dynamics as demonstrated by increases in the output of the aurora and auroral kilometric radiation (AKR) at Saturn has been found to be driven by the rotation of the planet except during periods of strong solar wind compression of the magnetosphere (Desch 1982; Clarke et al. 2009; Crary et al. 2005; Badman and Cowley 2007; Masters et al. 2014; Badman et al. 2014). The influence of the solar wind at Jupiter is thought to be less strong although solar wind compressions have been associated with changes in the aurora (Baron et al. 1996; Gurnett et al. 2002; Nichols et al. 2007; Cowley et al. 2007; Clarke et al. 2009).

\subsection{Some examples of the effects of SEPs}

\subsubsection{Control of the radiation belts}

At the Earth, high-energy charged particles in the van Allen radiation belts and in SEP events can damage satellites on orbit leading to malfunctions and loss of satellite 
service (Horne et al. 2013). Recent studies have examined the possibility that the strength of Jupiter's radiation belts, as measured through its synchrotron radiation output, is affected by the solar UV/EUV output (Tsuchiya et al. 2011; Kita et al. 2013). The commonly accepted mechanism for driving radial diffusion at Jupiter and Saturn is electric field variations in the ionosphere driven by the neutral wind dynamo effect, which in turn are a result of solar heating of Jupiter's atmosphere by UV/EUV (Brice and McDonough mechanism 1973). The natural consequence of this scenario is that increases in solar output in this range would lead to an increase in the radial diffusion rates accelerating electrons and, therefore, to an increase of the intensity of the inner radiation belt electron population. Tsuchiya et al. (2011) demonstrated that short-term variations in the Jupiter Synchrotron output correlated positively with the Mg II solar UV/EUV index with a time lag of 3-5 days. Kita et al. (2013) also showed that the average ratio of the dawn/dusk asymmetry was likely related to the Brice and McDonough mechanism, but that the daily variations in the asymmetry did not correspond to the solar UV/EUV output. Changes in the UV output of the Sun are also thought to influence the electron radiation belts at Saturn (Krupp et al. 2014).

\subsubsection{A mixed particle/radiation effect: atmospheric escape-the case of Mars}

In this particular case, the fate of Mars' atmosphere during its encounter with solar energetic events is the object of a lot of attention because it is thought to mimic early solar system conditions (see Sects. 6.3 and 8). Many observations of the evolution of the ion escape rate under various solar conditions have been reported, in particular the increase of a few times up to one order of magnitude of the atmospheric escape rate during SEP and CIR encounters (Hara et al. 2011; Wei et al. 2012). The main point is that there is not a single process at the origin of the Mars' atmosphere escape, but a conjunction of mechanisms (Chassefière and Leblanc 2004; Lundin et al. 2007). However, all of them are linked to the solar wind and in some extend to solar activity through different mechanisms:

1. Ion sputtering: exospheric neutrals undergo collisions with energetic ions, picked up and swept away by solar wind magnetic lines, and finally re-impacting the high atmosphere. Mars' atmospheric escape has a strong connection to solar activity (Luhmann et al. 1987; Lundin et al. 2008): the solar EUV flux creates ions that can diffuse through the atmosphere and are taken away in the solar wind. An additional phenomenon may increase escape: the ions are sensitive to the interplanetary magnetic field and will spiral about the magnetic field lines. They can then re-enter the atmosphere, create a secondary ionization and secondary escape, referred to as "ion sputtering". Chaufray et al. (2007) show that the sputtering contribution to the total oxygen escape is smaller by one order of magnitude than the contribution due to dissociative recombination. The neutral escape is dominant at all solar activities.

2. From Lundin et al. (2007), the two preceding mechanisms are the most easily tested against empirical data. However, there are still a number of "nonthermal" electromagnetic acceleration processes that energize the plasma and create atmospheric escape. 
3. Another source of atmospheric escape is solar EUV flux. This is also a two-step mechanism. First, the EUV flux ionizes the gas above the exobase, allowing the ions to be picked up by the solar wind. The second mechanism is through double ionization: a doubly ionized molecule immediately dissociates into two singly ionized parts, which drift apart from each other because of Coulomb repulsion. The internal energy is converted into velocity, which may exceed the escape velocity (Lilensten et al. 2013).

Many missions and instruments provided key information on planetary space weather. At Mars, these include Mars Global Surveyor (MGS) which carried a magnetometer and electron instrument, and Mars Express which carried ion and electron spectrometers and neutral particle imagers. Recently, the NASA MAVEN mission was placed into orbit in September 2014 (Jakosky et al. 2014). On this mission, all relevant particle and field measurements will be made simultaneously for the first time. Its main objectives are to observe the present atmospheric erosion and to reconstruct its past evolution. MAVEN will, therefore, measure in situ and remotely the characteristics of Mars' upper atmosphere from its thermosphere/ionosphere up to its exosphere and Mars' electromagnetic environment. It will reconstitute the main escape paths in all escape mechanisms for the ionospheric ions (ion pick up and ionospheric escape) as well as for the neutral Martian atmospheric species (Jeans/hydrodynamic escape, sputtering, photo-chemical-induced escape) (Lillis et al. 2014). However, to extrapolate these escape mechanisms up to the early phases of our solar system, the observations of these escape paths during solar energetic events will provide key information on the way a planet like Mars evolved under early strong solar conditions. The solar wind speed and flux evolution with time are suggested by the observations of young solar analogs. Wood et al. (2014) observed the Lyman alpha absorption from the interaction between the stellar wind and the interstellar medium and reconstructed the intensity of the solar wind at various ages of solar-type stars. They concluded that the solar wind flux might have initially increased by few orders of magnitude with respect to current solar wind conditions during the first $700 \mathrm{Myr}$ of solar-type star and then decreased down to the current flux. In the same way, the EUV/UV flux is thought to have decreased by a few orders of magnitude since the beginning of our Sun (Ribas et al. 2005). The solar wind and flux conditions during the early phase of the Sun were, therefore, much closer to the situation during energetic Solar events than to quiet conditions. Space weather at Mars is, therefore, a key feature in understanding its past evolution.

\subsection{Habitability}

Habitability is commonly understood as "the potential of an environment (past or present) to support life of any kind". ${ }^{1}$ Based on the only known example of Earth, the

\footnotetext{
1 Steele A., Beaty D.W., Amend J., Anderson R., Beegle L., Benning L., Bhattacharya J., Blake D., Brinckerhoff W., Biddle J., Cady S., Conrad P., Lindsay J., Mancinelli R., Mungas G., Mustard J., Oxnevad K., Toporski J., and Waite H., 2005, "The Astrobiology Field Laboratory.", unpublished White Paper, 72 p, posted December 2005 by the Mars Exploration Program Analysis Group (MEPAG) at http://mepag.jpl. nasa.gov/reports/archive.html.
} 
concept refers to whether environmental conditions are available that could eventually support life, even if life does not occur currently (Javaux and Dehant 2010; Dehant et al. 2012). As mentioned in Dehant et al. (2012), an unambiguous definition of life is currently lacking, but one generally considers that life includes properties such as consuming nutrients and producing waste, the ability to reproduce and grow, pass on genetic information, evolve, and adapt to the varying conditions on a planet (as also mentioned by Sagan 1970). Terrestrial life requires liquid water. The stability of liquid water at the surface of a planet defines a habitable zone around a star (see e.g., Dole 1964; Shklovskii and Sagan 1966; Huang 1959, 1961; Hart 1980). In the solar system, it stretches between Venus and Mars, but excludes these two planets. If the greenhouse effect is taken into account, the habitable zone may have included early Mars while the case for Venus is still debated.

As envisaged in Javaux and Dehant (2010), this definition of habitability may be developed and closely integrate the geophysical, geological, and biological aspects of habitability. In particular the role of the atmosphere is essential. Planetary atmospheres may or may not provide the necessary conditions for water to be liquid at the surface of these planets. The pressure conditions depend on the amount of atmosphere and the planetary mass. The temperature conditions depend on the ability of the atmosphere to provide a greenhouse effect as well as the distance of the planet to the Sun. Impacts of meteorites and comets also provide volatiles as well as induce significant atmospheric escape. They are particularly useful for the study of atmospheric evolution (erosion and delivery). In a similar way, planetary magnetic fields have long been considered as a shield protecting planetary atmospheres from erosion by solar wind. A magnetic field would prevent direct atmospheric erosion by the solar wind and trap planetary ions allowing for a substantial return flow into the atmosphere and reducing the net loss of atmospheric material. However, this view has been challenged by recent observations performed on Earth, Mars and Venus atmospheres. In particular, the amount of escaped planetary ions that returns to the ionosphere and the amount of escaped planetary material that returns back to the atmosphere under the effect of planetary magnetic field have been revised downwards (e.g., Nilsson et al. 2012; Fedorov et al. 2011). These present-day situations were probably even more pronounced earlier in the history of the solar system because at that time, the energy input from the Sun was large enough to allow lighter species in the atmosphere (Hydrogen mainly, but also Oxygen and $\mathrm{CO}_{2}$ ) to flow into space and to be removed from the atmosphere (hydrodynamic escape), which is not affected by the presence of a magnetic field. Such a mechanism has occurred during the first few hundred million years of the evolution when the solar wind was stronger than the present-day and the EUV flux could reach up to 100 times its present value (Tian et al. 2008). Moreover, at that time, the energy input from the Sun would have been high enough to lead to the expansion of the atmosphere well above its present-day altitudes and, possibly, well above the altitudes that are protected by the magnetic field (several planetary radii, see Ribas et al. 2010).

Solar energetic particles and GCRs also play an important role in habitability. The possible emergence of life on Mars 3.8 billion years ago, at about the same time as it was emerging on Earth, is a topic of interest for several space missions. At that time, Mars had a magnetic field, the evidence for this is the crustal fields referred to earlier, and its sudden disappearance initiated atmospheric loss and climate change on Mars. 
There is evidence that 3.8-4 billion years ago may have been habitable (Grotzinger et al. 2014). At the Earth, the magnetic field played a role as a cradle for life, offering protection from SEPs, GCRs and direct solar wind erosion of the atmosphere. The present-day Martian surface has poor habitability due to the thin $\mathrm{CO}_{2}$ atmosphere and the radiation environment from SEPs, galactic cosmic rays and indeed UV radiation. The Exo-Mars rover will, therefore, drill up to $2 \mathrm{~m}$ under the surface to search for signs of past life. Recent simulations of the subsurface Mars surface radiation environment (Dartnell et al. 2007) indicate that microbial survival times increase significantly with depth. Similar studies have started to model the environment in the clouds of Venus (Nordheim et al. 2014).

\section{Planetary space weather impacts on humans and technology}

The adopted definition of space weather clearly distinguishes between space weather as a study of a natural environment, and space weather as a discipline that is geared towards practical applications. After having addressed the first topics, let us now consider some specific examples of studies that address the space weather effects.

\subsection{Planetary space weather impacts on astronauts}

Human safety is of paramount concern for future planetary missions. SEPs are a major hazard here. Although intense events occur rarely, the resulting dose can be lethal for an unshielded astronauts. The radiation dose on the astronauts must clearly be monitored and, as our technology (e.g., spacecraft) may also be affected, the risk for satellite missions to the planets from SEP events, CME events and from local populations of high-energy particles such as the radiation belts must be evaluated. This has been particularly the case for the electronics of the ongoing Cassini mission to Saturn (Miner 2002; Russell 2003), and for the upcoming JUICE mission to Jupiter (Jupiter ICy moons Explorer) (Grasset et al. 2013). Close attention to the high-energy particle environment both on the way to other planets and once the spacecrafts are in orbit is required for which radiation models are used to plan the design of the spacecraft and instruments onboard. For example, Jupiter presents a very challenging environment with its intense radiation belts and the JOSE model (JOvian Specification Environment model, Sicard-Piet et al. 2011) has been used in planning for the JUICE mission once it is within the Jovian environment.

As we consider moving towards human exploration of Mars, space radiation and its effects on human health will be important to characterize, model, monitor and mitigate. As mentioned above, there are serious effects which could be encountered on the way to Mars as well as on the surface, including SEP events as well as background GCR. The RAD instrument on MSL recently indicated that, based on measurements made during the cruise phase and on the surface of Mars, the estimated dose for a typical manned mission profile would be about one Sievert (Hassler et al. 2014). This is the career limit for NASA astronauts and may provide an ultimate limit for such crewed endeavors. 


\subsection{Planetary space weather impacts on planetary missions}

There are a number of documented impacts of space weather effects on planetary mission spacecraft and their instruments, some of which compromise the hardware or software directly, while others temporarily interfere with measurements, stored data, or communications. A notable example of the former includes the failure of the MARIE radiation detector on Mars Odyssey (Andersen 2006) due to presumed damage to onboard electronics from the unusually intense SEP events of October-November 2003. The communication system on the Nozomi spacecraft was temporarily disabled by a solar flare in April, 2002 (Miyasaka et al. 2003). Examples of effects on measurements include the radiation backgrounds from SEPs that render it difficult to evaluate Mars ion escape fluxes with ASPERA-3 on Mars Express during a major space weather event (Futaana et al. 2008), and loss of ground and subsurface reflection capability of the Mars Express MARSIS radar experiment during solar particle events (Espley et al. 2007).

The heliospheric cosmic ray environment is directly influenced by solar activity. Solar cosmic rays and energetic particle events are intrinsically linked to active events on the Sun. However, the concentration of GCRs is also modulated by the magnetic field of the Sun. When solar magnetic activity peaks at solar maximum, more GCRs are deflected away from the Earth. Conversely, the cosmic ray flux increases at solar minimum. In addition, intense heliospheric perturbations can create an effect on the GCR flux known as the Forbush decrease where a CME sweeps up a proportion of GCRs as the magnetic field changes such that fewer GCRs reach Earth.

The effects of cosmic rays and SEPs at planets with no humans present are restricted to the health and survival of spacecraft. The direct effects of such highly energetic particles are the penetrating radiation within spacecraft hardware with the potential to cause single event upsets, internal charging and degradation of solar panels (Jiggens et al. 2014). Other important effects arise when there is a geomagnetic storm, as one may encounter disruption of electrical systems, in particular on satellites and electrical power systems. Geomagnetic storms also cause important degradation in communication systems.

Satellite hardware damage can be caused by energetic solar particles because most of their electronic systems contain microchips that may be vulnerable, though they are tested to be resistant to a certain dose. Additionally charged particles may cause different portions of the spacecraft to be differentially charged, and possibly, cause electrical charges or discharges and arcs across spacecraft surfaces. The rays may also create false signals or commands. The spacecraft may then be disabled or put in "Safe Mode" (when all non-essential sub-systems are shut down and only essential functions such as radio reception and attitude control are active).

These effects on modern technology are very similar to those at Earth. Several planetary missions already suffered from such space weather events (Landis et al. 2006). Ideally, a widespread distribution of space weather monitors is needed, which may provide a solar system-wide characterization of conditions. ${ }^{2}$ The multi-scale and

\footnotetext{
2 See for example http://space-env.esa.int/index.php/online-resources.html.
} 
multi-instrument aspect of these observations is also an important issue (Leblanc et al. 2008).

Cosmic ray particles can also lead to indirect space weather effects. Cosmic Ray Albedo Neutron Decay (CRAND), for example, is a process by which high-energy particles are created, which contribute to the radiation belts at various planets (Kollmann et al. 2013; Roussos et al. 2011). This process is particularly important in creating the inner proton radiation belts at Saturn (Paranicas et al. 2008) and also the inner proton belt at the Earth (Selesnick et al. 2013). This process requires a good density of neutral atmospheric particles to be available such that many secondary neutrons are created by the impact of each cosmic ray particle. The decay of these neutrons releases protons and electrons, which, if created in the right region of space, can be trapped and contribute to the high-energy particles of the radiation belt. The process tends to be strongest closest to the planet. Such trapped high-energy particles (but not as high in energy as the original cosmic rays) are hazardous to any spacecraft passing through them, not just for the reasons alluded to earlier, but also from general surface and internal charging leading to the possibility of electrostatic discharge.

\subsection{Some planetary space weather impacts on space missions: role of atmospheres}

One specific, and increasingly relevant aspect of planetary space weather is the role of atmospheric drag in satellite aeroentry/aerobraking (Duvall et al. 2005; Doornbos and Klinkrad 2006; Forbes et al. 2006). The planets that are mainly concerned are: Venus, the Earth, Mars, Jupiter, Saturn, Uranus, Neptune, and Titan. The determination of this drag requires a specification of the neutral atmosphere density and its scale height, whose variability is mainly driven by the solar spectral irradiance in the UV. A second, but more intermittent contribution comes from Joule heating by ionospheric currents, which are driven by the response of the planetary magnetic field to the solar wind.

There are three important issues regarding aerobraking: the determination of the solar radiative forcing requires a continuous monitoring of the UV spectrum at any location along the Sun-planet line. For the Earth, this spectrum is often reduced to the single F10.7 index, which captures the salient features of the varying EUV flux. Other planets, however, because of their different atmospheric composition, require the monitoring of other bands of the UV. Solar proxies of the UV spectrum thus need to be tailored to each particular planet, see Sect. 8.2. A second issue is the climatology of the planet's atmosphere, with the specification of the atmospheric composition, and its vertical profile. Our knowledge of these quantities is often poor, thus requiring approximations. The third, and probably most challenging issue is the description of Joule heating, for which coupled solar wind-magnetosphere-ionosphere models are required, by lack of direct observations. At the Earth, these models can be conveniently driven the numerous existing geomagnetic observations, from which proxies such as the am and ap indices [which characterize the variation of the local or planetary magnetic fields (Menvielle and Marchaudon 2007) and references herein] can be derived. Clearly, there is no equivalent of these for other planets. For that reason, satellite drag on other planets can only be estimated on timescales of several days 
and beyond (assuming that the atmospheric composition and density are well known), while presently still ignoring short transients that are caused by the dynamics of the magnetosphere/ionosphere.

Since the state of the neutral atmosphere is intimately connected to that of the ionosphere, most requirements expressed by satellite operators also apply to users who are affected by the varying state of the ionosphere. In particular, continuous monitoring of the EUV flux is required to mitigate disruptions in satellite communication, and in remote sensing. Such disruptions are expected to occur at all planets, and also at the terminator of the Moon (Bothmer and Daglis 2006).

\subsection{Some planetary space weather impacts on space missions: role of the magnetosphere}

Mini-magnetospheres exist on the Moon and Mars, associated with crustal magnetic fields. Such structures modify the solar wind interaction with these bodies and have an effect on plasma escape at Mars. Recently, two interesting applications of minimagnetospheres have been presented, as follows:

- First, suggestions have been made about the use of the solar wind as an energy source for spacecraft propulsion, such as the "mini-magnetosphere plasma propulsion (M2P2)" idea (Winglee et al. 2000). In this approach, plasma injected into a magnetic field produced on a spacecraft plays the role of a mini-magnetosphere. As the plasma dynamic pressure decreases in the outer solar system the size of the magnetosphere increases, producing a constant force for continued acceleration even at large heliocentric distance. In principle, a system could move at $50-80 \mathrm{~km} \mathrm{~s}^{-1}$, much larger than conventional spacecraft speeds.

- In another idea, mini-magnetospheres are used in attempts to shield spacecraft from potentially damaging solar wind and even SEPs (Bamford et al. 2008; Gargaté et al. 2008). The suggestion is that, in addition to gyroradius deflection of the solar wind, energetic charged particles may be deflected by an electrostatic barrier built up by kinetic effects.

The practical problems, as well as issues with the modeling, mean that such systems at present remain untested in space although laboratory tests have been performed.

\section{Future of planetary space weather}

To become a mature field, planetary space weather needs to fulfill several needs (besides doing good science), both in term of knowledge and operability.

\subsection{A need for exploring the space environment outside of the ecliptic plane}

One of the side aspects of planetary space weather is the exploration of the space environment outside of the ecliptic plane. This topic is not driven by planetary space weather because all major bodies of our solar system lie very close to the ecliptic plane. The main motivation for moving away from this plane is to understand the 


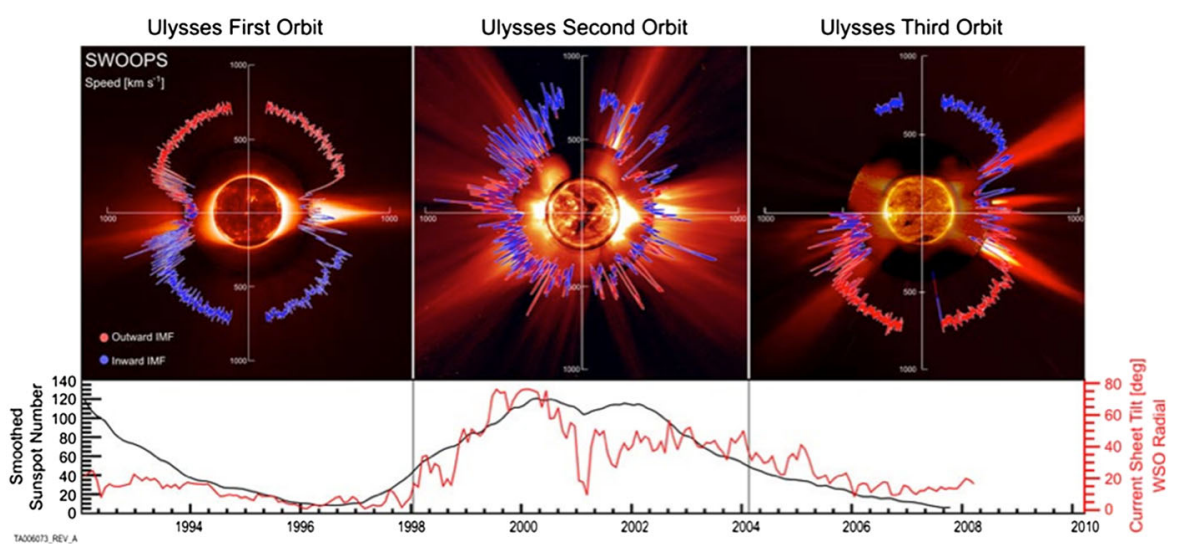

Fig. 3 Observations of the solar wind by Ulysses. A combination of plasma and magnetic field data were used to illustrate the changes between solar cycles (from McComas et al. 2008). The plasma velocity is shown as a function of the radial distance from the Sun, colored in blue for outward-directed magnetic field, and in red for inward-directed magnetic field, with the sunspot number for comparison

properties of solar activity near the poles of the Sun: what is the latitudinal anisotropy of the solar spectral irradiance, how do the sources of the solar wind change, how can we improve the observation of the latitudinal spread of CMEs, etc.

Ulysses was the first mission to really explore the outer ecliptic. Thanks to its unique combination of plasma and magnetic field instruments, this mission was able to reveal the large changes undergone by the solar wind during the solar cycle, and as a function of latitude (McComas et al. 2008). In Fig. 3, the plasma velocity is shown as a function of the radial distance from the Sun, colored in blue for outward-directed magnetic field and in red for inward-directed magnetic field, with the sunspot number for comparison. The plots show the slow (near ecliptic) and fast (polar) solar wind at solar minimum, and their more complex structure at solar maximum, together with the reversal of the magnetic field on an 11-year period. The solar wind composition and wave data further confirm the latitudinal variation of the solar wind characteristics, and the propagation of heliospheric disturbances. These results are highly relevant for determining the spread of CMEs (and their potential impact on planets), and for the specification of the satellite environment, with its associated risks. The next mission to explore the Sun and the solar wind out of the ecliptic will be Solar Orbiter, which is due for launch in 2017.

Future candidate missions to other bodies (e.g., MarcoPolo-R) or for monitoring the inner heliosphere (e.g., SPORT) may also move out of the ecliptic. Solar energetic particle events obviously represent the main space weather hazard for such missions. However, other, and more subtle effects should not be neglected. Changes in the photoelectron production rate, for example, are driven by the varying EUV flux, and modify the spacecraft floating potential (Peterson et al. 2013). Predicting, understanding and perhaps controlling this potential are important for correcting data from plasma instruments. Spacecraft charging may also lead to discharges, which affect spacecraft components. 
8.2 A need for space weather proxies for the solar UV flux at planets

The paucity of continuous and properly calibrated solar spectral irradiance measurements has stimulated the development of various proxies for specifying planetary environments. The most popular proxy for the EUV/UV band is solar radio flux at $10.7 \mathrm{~cm}$, which is better known as the F10.7 index. Other proxies include the sunspot number and the MgII core-to-wing index (Floyd et al. 2005; Snow et al. 2014). Although long and continuous EUV/UV observations are now becoming more routinely available, proxies are still likely to be preferred for a while, partly because so many atmosphere models have been tuned to them.

There are two issues regarding planetary environments. The first one, which also applies to our terrestrial environment, is how faithfully these proxies can match the solar spectral variability. No single proxy can properly reproduce the variability in a given spectral band at all timescales (Dudok de Wit et al. 2009). The recent deep solar minimum in addition has revealed the existence of significant discrepancies between the trend of some proxies, e.g., Tapping and Valdés (2011).

In most applications, the choice of a proper proxy is not a major issue, given the large uncertainties in the observations, and the F10.7 is a reasonable fallback. In some cases, proxies have been tailored to the environment, either empirically (Martinecz et al. 2008), or by modeling the atmospheric response, e.g., with the aeronomy of Ganymede (Barthélemy and Cessateur 2014).

The second issue, which is specific to planets, is about the longitude of the observations in a heliocentric frame. For terrestrial space weather, there is no major incentive for specifying the solar spectral irradiance away from the Sun-Earth line, apart for making predictions. For planetary space weather, however, terrestrial observations of the Sun are rarely adequate since fast transients such as flares may go unnoticed. Future missions that are going far out of the ecliptic will also benefit from latitudinally dependent specifications of the spectral irradiance since the latter has recently been shown to change when moving out of the ecliptic (Vieira et al. 2012).

The Stereo mission has revealed how important a series of solar sentinels at different longitudes would be for monitoring flares and other space weather hazards (Foullon et al. 2005). There is presently no good alternative to direct spectral irradiance observations, especially when fast transients are present. One way out is to use a combination of far side imaging in the Lyman- $\alpha$ line (presently done by SWAN onboard SoHO), with irradiance models that are based on the evolution of photospheric magnetic field (Fontenla et al. 2009). Another way is to use the variations in photoelectron energy spectra to monitor EUV and XUV irradiance variability. This has been explored in the environments of Mars (Mitchell et al. 2001), and the Earth (Peterson et al. 2013). This approach, however, suffers from a degeneracy of the reconstructed EUV flux with regard to the measured photoelectron spectra.

\subsection{A need for space weather proxies for magnetic activity}

In many space weather applications, approximate but routinely available proxies are often preferable to physically more pertinent observables. This is particularly true for 
the specification of the ionosphere, for which the problem of finding good proxies is not restricted to the UV forcing only, but also to Joule heating, and to its magnetic proxies, see Sect. 7.3. Although magnetic activity is ultimately driven by solar variability, the connection between the two is too complex to be used in a meaningful way, except for statistical purposes (Richardson 2013).

On the Earth, many geomagnetic indices have been designed by making use of the large number of ground-based observatories, with more than one century of experience. There is nothing equivalent for other planets. Most of the magnetic data from Mars, for example, are still derived by orbit mapping (Acuña et al. 2001), while ground observations are still at their infancy only (Vennerstrom et al. 2012). Therefore, the equivalence of geomagnetic proxies for planets is still an open field to be explored. Given the importance of such proxies for various space weather applications (including the definition of maximum useable frequency for telecommunications, or the specification of the radiative environment for manned spaceflight around the planet), there is no doubt that new developments will emerge. For small bodies that are immersed in their parent's main magnetosphere, new types of proxies will certainly be required.

\subsection{A need for multi-point observations of the solar wind}

The knowledge of solar activity in general is a must as it is for terrestrial space weather. A review on its past, present and future may be found in Svalgaard (2013). However, for planetary space weather still more than for space weather, multi-point observations of the upstream solar wind, and the monitoring of the Sun from several vantage points are essential for properly predicting the impact of geoeffective events such as CMEs and SEPs (Futaana et al. 2008; Lugaz et al. 2012; Colaninno et al. 2013). These requirements apply equally to planetary space weather. However, since most of the dynamical evolution of the solar wind, and its magnetic field, occurs within $1 \mathrm{AU}$, in situ conditions can be relatively easily extrapolated beyond the terrestrial orbit. The real challenge is in obtaining in situ solar wind observations and solar monitoring at all longitudes, not just along the Sun-Earth line.

There have been a number of multi-point spacecraft observations at the planets that have shown how solar wind coupling is important for space weather at the planets. For example, although Venus does not have an intrinsic magnetic field, the solar wind magnetic field is draped around the ionosphere forming a bow-shock, a tail-like region and an induced magnetosphere. Changes in the clock angle of the solar wind magnetic field observed by Venus Express were related to changes in the draped field region field observed by MESSENGER and confirmed the importance of the IMF on induced magnetospheres (Slavin et al. 2009). At Mars, an increased outflow of heavy ions was observed by Mars Express during a period of high solar wind dynamic pressure measured by Rosetta, indicating that the solar wind can enhance the erosion of the ionosphere (Edberg et al. 2009). Multi-point observations by Cassini in the solar wind as it approached Jupiter and Galileo in the outer magnetosphere have also shown how an interplanetary shock and increased dynamic pressure can result in compression and electron heating in the outer magnetosphere and increased sub-corotation of plasma in the outer region (Hanlon et al. 2004b). The shock also enhanced radio emissions from 
the planet which, due to the motion of the source regions, also indicated increased sub-co-rotation (Hess et al. 2014). Previous multi-point observations have also indicated that reversals in the north-south component of the interplanetary magnetic field control the magnetopause location (Kivelson and Southwood 2003), as at Earth. It is also important to note that multi-point measurements at the planets provide one of the best methods of testing models such as ENLIL which model the solar wind flow to beyond 1 AU. Observations of the solar magnetic field are used to drive a coronal model which is coupled to a heliospheric model based on ideal MHD (Odstrcil et al. 2004). During favorable alignments of the planets, in situ observations of the solar wind at Mercury, Venus, Earth and Mars provide valuable data to verify the model and develop better forecasts.

\subsection{A need for operability}

Already, space agencies have to take account of planetary space weather. This is the case for aerobraking for example at Mars (Moudden and Forbes 2010) or Venus (Hibbard et al. 2012). In the next years, the cases for planetary space weather predictions will increase, as shown above. There will be a need to understand the worst cases at each planet or planetary body (see e.g., Lario 2012) to send manned missions without exposing the astronauts to space weather hazards. There will be also a need to run models in real or near real time. Many problems that Earth space weather already encountered will be met for planetary space weather. The main one is operability, i.e., the ability to be ready for use, to provide the optimum result and to provide real time or near real time predictions (Tsagouri et al. 2013). Several space weather centers already exist in all continents, in Boulder (Colorado, USA) (Crown 2012), in Brussels (Belgium) (Berghmans et al. 2005), in UK (Exeter, UK Met Office), China (Beijing), Russia (Moscow), India (New Delhi), Canada (Ottawa), Czech Republic (Prague), Japan (Tokyo), Australia (Sydney), Sweden (Lund), Belgium (Brussels), Poland (Warsaw), South Africa (Hermanus), South Korea (Jeju), Brazil (São José dos Campos), Austria (Treffen), Spain (Madrid), France (Toulouse), ... Many of these regional space weather centers are networking (i.e., Watari and Boteler 2009). Large efforts for operability are under way. As an example, ESA's Space Situational Awareness (SSA) program ${ }^{3}$ aims to support Europe's independent utilization of, and access to, space through the provision of timely and accurate information and data regarding the space environment, and particularly regarding hazards to infrastructure in orbit and on the ground.

Whether the planetary space weather operation centers will be part of the Earth's ones or not is still to be decided, but there is little doubt that such centers will soon start to emerge.

$\overline{{ }^{3} \text { See http://swe.ssa.esa.int/web/guest. }}$ 


\section{Conclusion}

Space weather has so far largely been concerned with the near-Earth environment only, but this review has shown that a natural extension to planetary environments is awaiting, with opportunities for interdisciplinary interactions emerging. Planetary space weather could even be a discipline on its own, which encompasses space aeronomy and the space environment part of the comparative planetology, with connections to issues such as the habitability of planets.

There is no doubt that the interest in planetary space weather will increase in response to the growing presence of humans and satellites outside of geospace. Forthcoming missions to Mars, Jupiter and Uranus will drive the need for a better understanding the response of planetary environments to solar activity; in turn, they will help put terrestrial space weather in a broader perspective by revealing how solar perturbations evolve as they travel through the heliosphere. The triggering of auroras at different planets by interplanetary shocks (Prangé et al. 2004; Lamy et al. 2012; Barthélemy et al. 2014) is a beautiful but also highly illustrative example of this. Planetary space weather is also likely to give deeper insight in the physics and chemistry of planetary environments, in the same way as the dynamical response of the Earth's environment can be used to diagnose our terrestrial environment, and in particular the couplings between its atmospheric layers.

Practical applications of planetary space weather are not as mature as they are on the Earth, and probably never will be. There are obvious reasons for this, such as the lack of direct observations, or the much smaller need for operability. There are also structural reasons, such as the limited interest by military users. This review in addition shows that several conditions need to be fulfilled, both in term of knowledge and operability, before such applications can emerge. A large effort has been devoted to the specification of radiation belt environments, because this is of direct relevance to missions such as JUICE. In comparison, much less is known about the ionospheric environment of planets, which have direct bearing on radio communication, and on aerobraking.

Acknowledgments JL thanks Teresa Del Rio Gaztelurrutia for initiating this reflexion through fruitful discussions. EEW and RBH are funded through STFC grant ST/I001727/1. RBH is also funded by NERC. AJC acknowledges support from STFC and the UK space agency TDdW received funding from the European Community's Seventh Framework Programme FP7-SPACE-2012-2 under the Grant Agreement 313188 (SOLID project, projects.pmodwrc.ch/solid/).

Open Access This article is distributed under the terms of the Creative Commons Attribution License which permits any use, distribution, and reproduction in any medium, provided the original author(s) and the source are credited.

\section{References}

Acuña MH, Connerney JEP, Wasilewski P, Lin RP, Mitchell D, Anderson KA, Carlson CW, McFadden J, Rème H, Mazelle C, Vignes D, Bauer SJ, Cloutier P, Ness NF (2001) J Geophys Res (Solid Earth) 106:23403. doi:10.1029/2000JE001404

Andersen V (ed) (2006) Observations of cosmic ray modulation with MARIE. In: Bulletin of the American Astronomical Society, vol 38 
Anderson BJ, Johnson CL, Korth H, Purucker M, Winslow RM, Slavin JA, Solomon SC, McNutt RLJ, Raines JM, Zurbuchen TH (2011) Science 333:1859. doi:10.1126/science.1211001

Badman SV, Cowley SWH (2007) Ann Geophys 25:941. doi:10.5194/angeo-25-941-2007

Badman SV, Jackman CM, Nichols JD, Clarke JT, Gérard JC (2014) Icarus 231:137. doi:10.1016/j.icarus. 2013.12.004

Bagenal F, Dowling TE, McKinnon WB (2004) Jupiter: the planet, satellites and magnetosphere. Academic Press, London

Baker DN, Poh G, Odstrcil D, Arge CN, Benna M, Johnson CL, Korth H, Gershman DJ, Ho GC, McClintock WE, Cassidy TA, Merkel A, Raines JM, Schriver D, Slavin JA, Solomon SC, Trávníček PM, Winslow RM, Zurbuchen TH (2013) J Geophys Res (Space Phys) 118:45. doi:10.1029/2012JA018064

Bamford R, Gibson KJ, Thornton AJ, Bradford J, Bingham R, Gargate L, Silva LO, Fonseca RA, Hapgood M, Norberg C, Todd T, Stamper R (2008) Plasma Phys Control Fusion 50:124025. doi:10.1088/ $0741-3335 / 50 / 12 / 124025$

Banks P, Kockarts G (1973) Aeronomy. Academic Press, London

Baron RL, Owen T, Connerney JEP, Satoh T, Harrington J (1996) Icarus 120:437. doi:10.1006/icar.1996. 0063

Barthélemy M, Cessateur G (2014) Space Weather Space Clim (in press)

Barthélemy M, Lamy L, Menager H, Schulik M, Bernard D, Abgrall H, Roueff E, Cessateur G, Prangé R, Lilensten J (2014) Icarus 239:160. doi:10.1016/j.icarus.2014.05.035

Bauer SJ, Lammer H (2004) Planetary aeronomy: atmosphere environments in planetary systems. Springer, Berlin

Berghmans D, van der Linden RAM, Vanlommel P, Warnant R, Zhukov A, Robbrecht E, Clette F, Podladchikova O, Nicula B, Hochedez JF, Wauters L, Willems S (2005) Ann Geophys 23:3115. doi:10.5194/ angeo-23-3115-2005

Berrilli F, Casolino M, Del Moro D, Di Fino L, Larosa M, Narici L, Piazzesi R, Picozza P, Scardigli S, Sparvoli R, Stangalini M, Zaconte V (2014) J Space Weather Space Clim 4:A16. doi:10.1051/swsc/ 2014014

Bolton SJ, Janssen M, Thorne R, Levin S, Klein M, Gulkis S, Bastian T, Sault R, Elachi C, Hofstadter M, Bunker A, Dulk G, Gudim E, Hamilton G, Johnson WTK, Leblanc Y, Liepack O, McLeod R, Roller J, Roth L, West R (2002) Nature 415:987

Bothmer V, Daglis IA (2006) Space weather: physics and effects. Springer, Berlin

Bougher SW, Blelly PL, Combi M, Fox JL, Mueller-Wodarg I, Ridley A, Roble RG (2008) Space Sci Rev 139:107. doi:10.1007/s11214-008-9401-9

Bougher SW, Borucki WJ (1994) J Geophys Res 99:3759. doi:10.1029/93JE03431

Bougher SW, McDunn TM, Zoldak KA, Forbes JM (2009) Geophys Res Lett 36:L05201. doi:10.1029/ 2008GL036376

Brice NM (1973) Planet Space Sci 21:1587. doi:10.1016/0032-0633(73)90065-2

Chamberlain JW (1964) Planet Space Sci 12:187. doi:10.1016/0032-0633(64)90147-3

Chanteur GM, Dubinin E, Modolo R, Fraenz M (2009) Geophys Res Lett 36:L23105. doi:10.1029/ 2009GL040235

Chassefière E, Leblanc F (2004) Planet Space Sci 52:1039. doi:10.1016/j.pss.2004.07.002

Chassefière E, Leblanc F, Langlais B (2007) Planet Space Sci 55:343. doi:10.1016/j.pss.2006.02.003

Chaufray JY, Modolo R, Leblanc F, Chanteur G, Johnson RE, Luhmann JG (2007) Geophys Res Lett (Planets) 112:9009. doi:10.1029/2007JE002915

Clarke JT, Nichols J, Gérard JC, Grodent D, Hansen KC, Kurth W, Gladstone GR, Duval J, Wannawichian S, Bunce E, Cowley SWH, Crary F, Dougherty M, Lamy L, Mitchell D, Pryor W, Retherford K, Stallard T, Zieger B, Zarka P, Cecconi B (2009) J Geophys Res (Space Phys) 114:5210. doi:10.1029/ 2008JA013694

Coates AJ (1999) R Soc Lond Philos Trans Ser A 357:3299. doi:10.1098/rsta.1999.0495

Coates AJ (2001) Our solar system and beyond in the new millennium. In: Thompson JMT (ed) Visions of the future: astronomy and earth science. Cambridge University Press, Cambridge

Coates AJ, Wellbrock A, Lewis GR, Arridge CS, Crary FJ, Young DT, Thomsen MF, Reisenfeld DB, Sittler EC Jr, Johnson RE, Szego K, Bebesi Z, Jones GH (2012) J Geophys Res (Space Phys) 117:A05324. doi:10.1029/2012JA017595

Colaninno RC, Vourlidas A, Wu CC (2013) J Geophys Res (Space Phys) 118:6866. doi:10.1002/ 2013JA019205 
Coustenis A, Atreya S, Ferrari C, Lebreton JP, Matson D, Spilker L, Strobel D (2006) Planet Space Sci 54:1115. doi:10.1016/j.pss.2006.06.005

Coustenis A, Atreya S, Ferrari C, Spilker L (2008a) Planet Space Sci 56:1. doi:10.1016/j.pss.2007.09.010

Coustenis A, Atreya S, Casavecchia P, Castillo J, Dutuit O, Hussmann H, Sohl F (2008b) Planet Space Sci 56:1571. doi:10.1016/j.pss.2008.08.015

Coustenis A, Atreya S, Castillo J, Coll P (2009) Planet Space Sci 57:1523. doi:10.1016/j.pss.2009.09.009

Coustenis A, Atreya S, Castillo J, Coll P (2010) Planet Space Sci 58:1665. doi:10.1016/j.pss.2010.09.001

Coustenis A, Atreya S, Castillo J, Coll P, Mueller-Wodarg I, Spilker L (2012) Planet Space Sci 61:1. doi:10. 1016/j.pss.2011.12.014

Coustenis A, Atreya S, Castillo J, Coll P, Mueller-Wodarg I, Spilker L (2013a) Planet Space Sci 77:1. doi:10. 1016/j.pss.2013.01.002

Coustenis A, Atreya S, Castillo J, Coll P, Mueller-Wodarg I, Spilker L (2013b) Planet Space Sci 88:1. doi:10.1016/j.pss.2013.10.010

Coustenis A, Ferrari C, Atreya SK, Spilker LJ (2005) Planet Space Sci 53:459. doi:10.1016/j.pss.2004.12. 001

Cowley SWH, Nichols JD, Andrews DJ (2007) Ann Geophys 25:1433. doi:10.5194/angeo-25-1433-2007

Crary FJ, Clarke JT, Dougherty MK, Hanlon PG, Hansen KC, Steinberg JT, Barraclough BL, Coates AJ, Gérard JC, Grodent D, Kurth WS, Mitchell DG, Rymer AM, Young DT (2005) Nature 433:720. doi:10. 1038 /nature 03333

Crown MD (2012) Space Weather 10:S06006. doi:10.1029/2011SW000760

Danilov D (1994) J Atmos Terr Phys 56:1213

Dartnell LR, Desorgher L, Ward JM, Coates AJ (2007) Geophys Res Lett 34:L02207. doi:10.1029/ 2006GL027494

Dehant V, Doris B, Philippe C, Vinciane D, Johan DK, Emmanuelle J, Steven G, Özgur K, Tilman S, Ann Carine V, Frank V, Tim VH, Valérie W (2012) Planet Space Sci 72:3. doi:10.1016/j.pss.2012.05.018

de Pater I, Dunn DE (2003) Icarus 163:449. doi:10.1016/S0019-1035(03)00068-X

de Pater I, Lissauer JJ (2010) Planetary sciences. Cambridge University Press, Cambridge. ISBN: 978-0521-85371-2

Decker RB, Krimigis SM, Roelof EC, Hill ME, Armstrong TP, Gloeckler G, Hamilton DC, Lanzerotti LJ (2005) Science 309:2020. doi:10.1126/science.1117569

Deng Y, Ridley AJ, Wang W (2008) J Geophys Res (Space Phys) 113:A09302. doi:10.1029/2008JA013081

Desch MD (1982) J Geophys Res (Space Phys) 87:4549. doi:10.1029/JA087iA06p04549

Di Fino L, Zaconte V, Stangalini M, Sparvoli R, Picozza P, Piazzesi R, Narici L, Larosa M, Del Moro D, Casolino M, Berrilli F, Scardigli S (2014) J Space Weather Space Clim 4:A19. doi:10.1051/swsc/ 2014015

Dickinson RE, Ridley EC (1975) J Atmos Sci 32:1219. doi:10.1175/1520-0469(1975)032<1219: ANMFTD $>2.0 . \mathrm{CO} ; 2$

Dole L (1964) Habitable planets for man. NewYork, Elsevier

Doornbos E, Klinkrad H (2006) Adv Space Res 37:1229. doi:10.1016/j.asr.2005.04.097

Dorman L (2009) Cosmic rays in magnetospheres of the earth and other planets, vol 358. Astrophysics and Space Science Library, Springer, Berlin

Dorman LI (2012) Ann Geophys 30:9. doi:10.5194/angeo-30-9-2012

Dudok de Wit T, Kretzschmar M, Lilensten J, Woods T (2009) Geophys Res Lett 36:10107. doi:10.1029/ 2009GL037825

Dungey JW (1962) J Phys Soc Jpn Suppl 17:B15

Dutuit O, Carrasco N, Thissen R, Vuitton V, Alcaraz C, Pernot P, Balucani N, Casavecchia P, Canosa A, Le Picard S, Loison JC, Herman Z, Zabka J, Ascenzi D, Tosi P, Franceschi P, Price SD, Lavvas P (2013) Astrophys J Suppl 204:20. doi:10.1088/0067-0049/204/2/20

Duvall AL, Justus CG, Keller VW (2005) In: 3rd international planetary probe workshop (Anavyssos, Attiki, Greece), vol 27, 20060004756 (NASA Marshall Space Flight Center, Huntsville, USA, 2005)

Edberg NJT, Auster U, Barabash S, Bößwetter A, Brain DA, Burch JL, Carr CM, Cowley SWH, Cupido E, Duru F, Eriksson AI, Fränz M, Glassmeier KH, Goldstein R, Lester M, Lundin R, Modolo R, Nilsson H, Richter I, Samara M, Trotignon JG (2009) Ann Geophys 27:4533. doi:10.5194/angeo-27-4533-2009

Edberg NJT, Nilsson H, Futaana Y, Stenberg G, Lester M, Cowley SWH, Luhmann JG, McEnulty TR, Opgenoorth HJ, Fedorov A, Barabash S, Zhang TL (2011) J Geophys Res (Space Phys) 116:A09308. doi:10.1029/2011JA016749

Engels S, van Geel B (2012) J Space Weather Space Clim 2:A09. doi:10.1051/swsc/2012009 
Enghoff MB, Pedersen JOP, Uggerhøj UI, Paling SM, Svensmark H (2011) Geophys Res Lett 38:L09805. doi:10.1029/2011GL047036

Erlykin AD, Gyalai G, Kudela K, Sloan T, Wolfendale AW (2009) J Atmos Solar Terr Phys 71:823. doi:10. 1016/j.jastp.2009.03.007

Erlykin AD, Sloan T, Wolfendale AW (2010) J Atmos Solar Terr Phys 72:151. doi:10.1016/j.jastp.2009. 11.002

Espley JR, Farrell WM, Brain DA, Morgan DD, Cantor B, Plaut JJ, Acuña MH, Picardi G (2007) Geophys Res Lett 34:L09101. doi:10.1029/2006GL028829

Fang X, Bougher SW, Johnson RE, Luhmann JG, Ma Y, Wang YC, Liemohn MW (2013) Geophys Res Lett 40. doi:10.1002/grl.50415

Fedorov A, Barabash S, Sauvaud JA, Futaana Y, Zhang TL, Lundin R, Ferrier C (2011) J Geophys Res (Space Phys) 116:7220. doi:10.1029/2011JA016427

Floyd L, Newmark J, Cook J, Herring L, McMullin D (2005) J Atmos Solar Terr Phys 67:3. doi:10.1016/j. jastp.2004.07.013

Fontenla JM, Quémerais E, González Hernández I, Lindsey C, Haberreiter M (2009) Adv Space Res 44:457. doi:10.1016/j.asr.2009.04.010

Forbes JM, Bruinsma S, Lemoine FG (2006) Science 312:1366. doi:10.1126/science.1126389

Foullon C, Crosby N, Heynderickx D (2005) Space Weather 3:S07004. doi:10.1029/2004SW000134

Fox JL, Galand MI, Johnson RE (2008) Space Sci Rev 139:3. doi:10.1007/s11214-008-9403-7

Futaana Y, Barabash S, Yamauchi M, McKenna-Lawlor S, Lundin R, Luhmann JG, Brain D, Carlsson E, Sauvaud JA, Winningham JD, Frahm RA, Wurz P, Holmström M, Gunell H, Kallio E, Baumjohann W, Lammer H, Sharber JR, Hsieh KC, Andersson H, Grigoriev A, Brinkfeldt K, Nilsson H, Asamura K, Zhang TL, Coates AJ, Linder DR, Kataria DO, Curtis CC, Sandel BR, Fedorov A, Mazelle C, Thocaven JJ, Grande M, Koskinen HEJ, Sales T, Schmidt W, Riihela P, Kozyra J, Krupp N, Woch J, Fränz M, Dubinin E, Orsini S, Cerulli-Irelli R, Mura A, Milillo A, Maggi M, Roelof E, Brandt P, Szego K, Scherrer J, Bochsler P (2008) Planet Space Sci 56:873. doi:10.1016/j.pss.2007.10.014

Gargaté L, Bingham R, Fonseca RA, Bamford R, Thornton A, Gibson K, Bradford J, Silva LO (2008) Plasma Phys Control Fusion 50(7):074017. doi:10.1088/0741-3335/50/7/074017

Goertz CK, van Allen JA, Thomsen MF (1979) J Geophys Res 84:87. doi:10.1029/JA084iA01p00087

González-Galindo F, Forget F, López-Valverde MA, M. Angelats i Coll, Millour E (2009) J Geophys Res (Planets) 114:E04001. doi:10.1029/2008JE003246

Grasset O, Dougherty MK, Coustenis A, Bunce EJ, Erd C, Titov D, Blanc M, Coates A, Drossart P, Fletcher LN, Hussmann H, Jaumann R, Krupp N, Lebreton JP, Prieto-Ballesteros O, Tortora P, Tosi F, Van Hoolst T (2013) Planet Space Sci 78:1. doi:10.1016/j.pss.2012.12.002

Grodent D (2014) Space Sci Rev. doi:10.1007/s11214-014-0052-8

Gronoff G, Lilensten J, Desorgher L, Flückiger E (2009a) Astron Astrophys 506:955. doi:10.1051/ 0004-6361/200912371

Gronoff G, Lilensten J, Modolo R (2009b) Astron Astrophys 506:965. doi:10.1051/0004-6361/200912125

Gronoff G, Mertens C, Lilensten J, Desorgher L, Flückiger E, Velinov P (2011) Astron Astrophys 529:A143. doi:10.1051/0004-6361/201015675

Grotzinger DY et al (2014) Science 343:1244797. doi:10.1126/science.1244777

Gubby R (2002) J Atmos Solar Terr Phys 64:1723. doi:10.1016/S1364-6826(02)00122-0

Gurnett DA, Kurth WS, Hospodarsky GB, Persoon AM, Zarka P, Lecacheux A, Bolton SJ, Desch MD, Farrell WM, Kaiser ML, Ladreiter HP, Rucker HO, Galopeau P, Louarn P, Young DT, Pryor WR, Dougherty MK (2002) Nature 415:985

Halekas JS, Delory GT, Lin RP, Stubbs TJ, Farrell WM (2009) J Geophys Res 114:A05110. doi:10.1029/ 2009JA014113

Hanlon PG, Dougherty MK, Forsyth RJ, Owens MJ, Hansen KC, Tóth G, Crary FJ, Young DT (2004a) J Geophys Res (Space Phys) 109:9. doi:10.1029/2003JA010112

Hanlon PG, Dougherty MK, Krupp N, Hansen KC, Crary FJ, Young DT, Tóth G (2004b) J Geophys Res (Space Phys) 109:A09S09. doi:10.1029/2003JA010116

Hara T, Seki K, Futaana Y, Yamauchi M, Yagi M, Matsumoto Y, Tokumaru M, Fedorov A, Barabash S (2011) J Geophys Res (Space Phys) 116:2309. doi:10.1029/2010JA015778

Hart M (1980) Habitable zones about main sequence stars. In: Goldsmith D (ed) The quest for extraterrestrial life $\mathrm{p} 236$

Hassler DM, Zeitlin C, Wimmer-Schweingruber RF, Ehresmann B, Rafkin S, Eigenbrode JL, Brinza DE, Weigle G, Böttcher S, Böhm E et al (2014) Science 343:1244797. doi:10.1126/science.1244797 
Hastings D, Garrett H (eds) (1996) Spacecraft-environment interactions. Cambridge, University Press

Hess SLG, Echer E, Zarka P, Lamy L, Delamere PA (2014) Planet Space Sci 99:136. doi:10.1016/j.pss. 2014.05.015

Hibbard K, Glaze L, Prince J (2012) Acta Astronaut 73:137. doi:10.1016/j.actaastro.2011.11.008

Hood LL (1983) J Geophys Res (Space Phys) 88:808. doi:10.1029/JA088iA02p00808

Horne RB, Glauert SA, Meredith NP, Koskinen H, Vainio R, Afanasiev A, Ganushkina NY, Amariutei OA, Boscher D, Sicard A, Maget V, Poedts S, Jacobs C, Sanahuja B, Aran A, Heynderickx D, Pitchford D (2013) J Space Weather Space Clim 3:A20. doi:10.1051/swsc/2013042

Horne RB, Thorne RM, Glauert SA, Menietti JD, Shprits YY, Gurnett DA (2008) Nature Phys 4:301-304. doi:10.1038/nphys897

Horne RB, Thorne RM, Shprits YY, Meredith NP, Glauert SA, Smith AJ, Kanekal SG, Baker DN, Engebretson MJ, Posch JL, Spasojevic M, Inan US, Pickett JS, Decreau PME (2005) Nature 437:227. doi:10. 1038/nature03939

Huang S (1959) Astron Soc Pac 71:421. doi:10.1086/127417

Huang S (1961) Sky Telesc 21:312

Jackman CH, Deland MT, Labow GJ, Fleming EL, Weisenstein DK, Ko MKW, Sinnhuber M, Anderson J, Russell JM (2005a) Adv Space Res 35:445. doi:10.1016/j.asr.2004.09.006

Jackman CH, Deland MT, Labow GJ, Fleming EL, Weisenstein DK, Ko MKW, Sinnhuber M, Russell JM (2005b) J Geophys Res (Space Phys) 110:A09S27. doi:10.1029/2004JA010888

Jakosky BM, Lin RP, Grebowsky JM, Luhmann J, Brain D, Lillis R (2014) Space Sci Rev (in Press)

Javaux EJ, Dehant V (2010) Astron Astrophys Rev 18:383. doi:10.1007/s00159-010-0030-4

Jiggens P, Chavy-Macdonald MA, Santin G, Menicucci A, Evans H, Hilgers A (2014) J Space Weather Space Clim 4:A20. doi:10.1051/swsc/2014017

Johnson RE (1990) Energetic charged particle interactions with atmospheres and surfaces. Springer, Berlin

Kallio E, Janhunen P (2003) Geophys Res Lett 30:1877. doi:10.1029/2003GL017842

Kita H, Misawa H, Tsuchiya F, Tao C, Morioka A (2013) J Geophys Res (Space Phys) 118:6106. doi:10. 1002/jgra.50568

Kivelson MG, Khurana KK, Russell CT, Volwerk M, Walker RJ, Zimmer C (2000) Science 289:1340. doi:10.1126/science.289.5483.1340

Kivelson MG, Khurana KK, Volwerk M (2002) Icarus 157:507. doi:10.1006/icar.2002.6834

Kivelson MG, Russel CT (1995) Introduction to space physics. Cambridge University Press, Cambridge. ISBN: 0-521-45104-3

Kivelson MG, Southwood DJ (2003) Planet Space Sci 51:891. doi:10.1016/S0032-0633(03)00075-8

Kollmann P, Roussos E, Paranicas C, Krupp N, Haggerty DK (2013) Icarus 222:323. doi:10.1016/j.icarus. 2012.10.033

Kopp G, Lean JL (2011) Geophys Res Lett 38:L01706. doi:10.1029/2010GL045777

Krasnopolsky VA (2002) J Geophys Res (Planets) 107:5128. doi:10.1029/2001JE001809

Krimigis SM, Roelof EC, Decker RB, Hill ME (2011) Nature 474:359. doi:10.1038/nature10115

Krupp A, Paranicas C, Carbary JF, Kollmann P, Krimigis SM, Mitchell DG (2014) Planet Space Sci. doi:10. 1016/j.pss.2014.03.021 (in press)

Kurth WS (1992) Adv Space Res 12:83. doi:10.1016/0273-1177(92)90380-G

Kutiev I, Tsagouri I, Perrone L, Pancheva D, Mukhtarov P, Mikhailov A, Lastovicka J, Jakowski N, Buresova D, Blanch E, Andonov B, Altadill D, Magdaleno S, Parisi M, Miquel Torta J (2013) J Space Weather Space Clim 3:A06. doi:10.1051/swsc/2013028

Laken BA, Calogovic J (2013) J Space Weather Space Clim 3:A29. doi:10.1051/swsc/2013051

Laken BA, Pallé E, Calogovic J, Dunne EM (2012) J Space Weather Space Clim 2:A18. doi:10.1051/swsc/ 2012018

Lamy L, Prangé R, Hansen KC, Clarke JT, Zarka P, Cecconi B, Aboudarham J, André N, BranduardiRaymont G, Gladstone R, Barthélémy M, Achilleos N, Guio P, Dougherty MK, Melin H, Cowley SWH, Stallard TS, Nichols JD, Ballester G (2012) Geophys Res Lett 39:L07105. doi:10.1029/ 2012GL051312

Landis GA, Bailey SG, Tischler R (2006) Conference record of the 2006 IEEE 4th World conference on photovoltaic energy conversion, vol 2. pp 1943. doi:10.1109/WCPEC.2006.279878

Lario D (2012) Space Weather 10:S03002. doi:10.1029/2011SW000732

Lean JL (1997) Ann Rev Astron Astrophys 35:33. doi:10.1146/annurev.astro.35.1.33 
Leblanc F, Chassefière E, Johnson RE, Hunten DM, Kallio E, Delcourt DC, Killen RM, Luhmann JG, Potter AE, Jambon A, Cremonese G, Mendillo M, Yan N, Sprague AL (2007) Planet Space Sci 55:1069. doi:10.1016/j.pss.2006.11.008

Leblanc F, Doressoundiram A, Schneider N, Massetti S, Wedlund M, López Ariste A, Barbieri C, Mangano V, Cremonese G (2009) Geophys Res Lett 36:7201. doi:10.1029/2009GL038089

Leblanc F, Witasse O, Lilensten J, Frahm RA, Safaenili A, Brain DA, Mouginot J, Nilsson H, Futaana Y, Halekas J, HolmströM M, Bertaux JL, Winningham JD, Kofman W, Lundin R (2008) J Geophys Res (Space Phys) 113:8311. doi:10.1029/2008JA013033

Lilensten J, Belehaki A (2011) Acta Geophys 57:1. doi:10.2478/s11600-008-0081-3

Lilensten J, Blelly PL (2000) Du soleil a la terre. Collection Grenoble Sciences, EDP Sciences, Paris. ISBN 2-7061-0834-7

Lilensten J, Dudok de Wit T, Kretzschmar M, Amblard PO, Moussaoui S, Aboudarham J, Auchère F (2008) Ann Geophys 26:269. doi:10.5194/angeo-26-269-2008

Lilensten J, Simon Wedlund C, Barthélémy M, Thissen R, Ehrenreich D, Gronoff G, Witasse O (2013) Icarus 222:169. doi:10.1016/j.icarus.2012.09.034

Lillis RJ, Brain DA, Bougher SW, Leblanc F, Luhmann JG, Jakosky BM, Modolo R, Fox J, Deighan J, Fang X, Wang YC, Lee Y, Dong C, Ma Y, Cravens T, Andersson L, Curry SM, Schneider N, Combi M, Stewart I, Clarke J, Grebowsky J, Mitchell DL, Yelle R, Nagy AF, Baker D, Lin RP (2014) Space Sci Rev

López-Puertas M, Funke B, Gil-López S, von Clarmann T, Stiller GP, Höpfner M, Kellmann S, Fischer H, Jackman CH (2005) J Geophys Res (Space Phys) 110:A09S43. doi:10.1029/2005JA011050

Lorenzato L, Sicard A, Bourdarie S (2012) J Geophys Res (Space Phys) 117:A08214. doi:10.1029/ 2012JA017560

Lugaz N, Kintner P, Möstl C, Jian LK, Davis CJ, Farrugia CJ (2012) Solar Phys 279:497. doi:10.1007/ s11207-012-0007-8

Luhmann JG, Russell CT, Scarf FL, Brace LH, Knudsen WC (1987) J Geophys Res 92:8545

Lundin R, Barabash S, Fedorov A, Holmström M, Nilsson H, Sauvaud J, Yamauchi M (2008) Geophys Res Lett 35:9203. doi:10.1029/2007GL032884

Lundin R, Lammer H, Ribas I (2007) Space Sci Rev 129:245. doi:10.1007/s11214-007-9176-4

Mall U, Kirsch E, Cierpka K, Wilken B, Söding A, Neubauer F, Gloeckler G, Galvin A (1998) Geophys Res Lett 25:3799. doi:10.1029/1998GL900003

Martinecz C, Fränz M, Woch J, Krupp N, Roussos E, Dubinin E, Motschmann U, Barabash S, Lundin R, Holmström M, Andersson H, Yamauchi M, Grigoriev A, Futaana Y, Brinkfeldt K, Gunell H, Frahm RA, Winningham JD, Sharber JR, Scherrer J, Coates AJ, Linder DR, Kataria DO, Kallio E, Sales T, Schmidt W, Riihela P, Koskinen HEJ, Kozyra JU, Luhmann J, Russell CT, Roelof EC, Brandt P, Curtis CC, Hsieh KC, Sandel BR, Grande M, Sauvaud JA, Fedorov A, Thocaven JJ, Mazelle C, McKennaLawler S, Orsini S, Cerulli-Irelli R, Maggi M, Mura A, Milillo A, Wurz P, Galli A, Bochsler P, Asamura K, Szego K, Baumjohann W, Zhang TL, Lammer H (2008) Planet Space Sci 56:780. doi:10.1016/j. pss.2007.07.007

Masters A, Fujimoto M, Hasegawa H, Russell CT, Coates AJ, Dougherty MK (2014) Geophys Res Lett 41:1862. doi:10.1002/2014GL059288

Mauk BH, Fox NJ (2010) J Geophys Res (Space Phys) 115:A12220. doi:10.1029/2010JA015660

McComas DJ, Ebert RW, Elliott HA, Goldstein BE, Gosling JT, Schwadron NA, Skoug RM (2008) Geophys Res Lett 35:18103. doi:10.1029/2008GL034896

McKenna-Lawlor SMP, Dryer M, Fry CD, Smith ZK, Intriligator DS, Courtney WR, Deehr CS, Sun W, Kecskemety K, Kudela K, Balaz J, Barabash S, Futaana Y, Yamauchi M, Lundin R (2008) J Geophys Res (Space Phys) 113:A06101. doi:10.1029/2007JA012577

Mendillo M, Nagy AF, Waite JH (2011) Atmospheres in the solar system. CRC Press, Boca Raton

Menietti JD, Shprits YY, Horne RB, Woodfield EE, Hospodarsky GB, Gurnett DA (2012) J Geophys Res (Space Phys) 117:A12214. doi:10.1029/2012JA018187

Menvielle M, Marchaudon A (2007) In: Lilensten J (ed) Space weather: research towards applications in Europe 2nd European Space Weather Week (ESWW2), Astrophysics and Space Science Library, vol 344. p 277. doi:10.1007/1-4020-5446-724

Mertens CJ, Kress BT, Wiltberger M, Blattnig SR, Slaba TS, Solomon SC, Engel M (2010) Space Weather 8:S03006. doi:10.1029/2009SW000487

Meyer-Vernet N (2007) Basics of the solar wind. Cambridge University Press, Cambridge 
Miletsky EV, Ivanov VG, Nagovitsyn YA, Jungner H (2004) Solar Phys 224:77. doi:10.1007/ s11207-005-4987-5

Miller S, Stallard T, Smith C et al (2006) R Soc Lond Philos Trans Ser A 364:3121. doi:10.1098/rsta.2006. 1877

Miner ED (2002) In: Bohlender DA, Durand D, Handley TH (eds) Astronomical data analysis software and systems XI. Astronomical society of the Pacific Conference series, vol 281. p 373

Mishev AL, Velinov PIY, Mateev L, Tassev Y (2011) Adv Space Res 48:1232. doi:10.1016/j.asr.2011.06. 004

Mitchell DL, Lin RP, Mazelle C, Rème H, Cloutier PA, Connerney JEP, Acuña MH, Ness NF (2001) J Geophys Res 106:23419. doi:10.1029/2000JE001435

Miyasaka H, Nagata K, Doke T, Kikachi J, Maezawa K, Hasebe N, Yanagimachi T, Takashima T, Ihara A, Miki D (2003) International cosmic ray conference, vol 6. p 3265

Moudden Y, Forbes JM (2010) J Geophys Res (Planets) 115:E09005. doi:10.1029/2009JE003542

Mura A, Wurz P, Lichtenegger HIM, Schleicher H, Lammer H, Delcourt D, Milillo A, Orsini S, Massetti S, Khodachenko ML (2009) Icarus 200:111. doi:10.1016/j.icarus.2008.11.014

Nichols JD, Bunce EJ, Clarke JT, Cowley SWH, Gérard JC, Grodent D, Pryor WR (2007) J Geophys Res (Space Phys) 112:2203. doi:10.1029/2006JA012005

Nilsson H, Barghouthi IA, Slapak R, Eriksson AI, André M (2012) J Geophys Res (Space Phys) 117:11201. doi:10.1029/2012JA017974

Nilsson H, Carlsson E, Brain DA, Yamauchi M, Holmström M, Barabash S, Lundin R, Futaana Y (2010) Icarus 206:40. doi:10.1016/j.icarus.2009.03.006

Nordheim TA, Dartnell LR, Desorgher L, Coates AJ, Jones GH (2014) Icarus (in press)

Odstrcil D, Pizzo VJ, Linker JA, Riley P, Lionello R, Mikic Z (2004) J Atmos Solar Terr Phys 66:1311. doi:10.1016/j.jastp.2004.04.007

Ozima M, Seki K, Terada N, Miura YN, Podosek FA, Shinagawa H (2005) Nature 436:655. doi:10.1038/ nature 03929

Paranicas C, Mitchell DG, Krimigis SM, Hamilton DC, Roussos E, Krupp N, Jones GH, Johnson RE, Cooper JF, Armstrong TP (2008) Icarus 197:519. doi:10.1016/j.icarus.2008.05.011

Parker EN (1958) Astrophys J 128:664. doi:10.1086/146579

Peterson WK, Brain DA, Mitchell DL, Bailey SM, Chamberlin PC (2013) J Geophys Res (Space Phys) 118:7338. doi:10.1002/2013JA019251

Phillips KJH (1995) Guide to the Sun. Cambridge University Press, Cambridge

Potter AE, Morgan TH (1990) Science 248:835

Potter AE, Morgan TH, Killenv RM (1999) Planet Space Sci 47:1441-1448

Prangé R, Pallier L, Hansen KC, Howard R, Vourlidas A, Courtin R, Parkinson C (2004) Nature 432:78. doi: $10.1038 /$ nature 02986

Rees MH (1974) Science 186:1200. doi:10.1126/science.186.4170.1200

Rees MH (1989) Physics and chemistry of the upper atmosphere. Cambridge University Press, Cambridge Ribas I, Guinan EF, Gudel M, Audard M (2005) Astrophys J 622:680-694

Ribas I, Porto de Mello GF, Ferreira LD, Hébrard E, Selsis F, Catalán S, Garcés A, do Nascimento JD Jr, de Medeiros JR (2010) Astrophys J 714:384. doi:10.1088/0004-637X/714/1/384

Richardson HV, Cane IG (2012a) J Space Weather Space Clim 2:A01. doi:10.1051/swsc/2012001

Richardson IG, Cane HV (2012b) J Space Weather Space Clim 2:A02. doi:10.1051/swsc/2012003

Richardson IG (2013) J Space Weather Space Clim 3:A08. doi:10.1051/swsc/2013031

Ridley AJ, Deng Y, Tóth G (2006) J Atmos Solar Terr Phys 68:839. doi:10.1016/j.jastp.2006.01.008

Rohen G, von Savigny C, Sinnhuber M, Llewellyn EJ, Kaiser JW, Jackman CH, Kallenrode MB, Schröter J, Eichmann KU, Bovensmann H, Burrows JP (2005) J Geophys Res (Space Phys) 110:A09S39. doi:10. 1029/2004JA010984

Romani PN, Bishop J, Bezard B, Atreya S (1993) Icarus 106:442. doi:10.1006/icar.1993.1184

Rouillard AP, Davies JA, Forsyth RJ, Savani NP, Sheeley NR, Thernisien A, Zhang TL, Howard RA, Anderson B, Carr CM, Tsang S, Lockwood M, Davis CJ, Harrison RA, Bewsher D, Fränz M, Crothers SR, Eyles CJ, Brown DS, Whittaker I, Hapgood M, Coates AJ, Jones GH, Grande M, Frahm RA, Winningham JD (2009) J Geophys Res (Space Phys) 114:7106. doi:10.1029/2008JA014034

Rouillard AP, Odstrcil D, Sheeley NR, Tylka A, Vourlidas A, Mason G, Wu CC, Savani NP, Wood BE, Ng CK, Stenborg G, Szabo A, Cyr OC St (2011) Astrophys J 735:7. doi:10.1088/0004-637X/735/1/7

Roussos E, Krupp N, Armstrong TP, Paranicas C, Mitchell DG, Krimigis SM, Jones GH, Dialynas K, Sergis N, Hamilton DC (2008) Geophys Res Lett 35:L22106. doi:10.1029/2008GL035767 
Roussos E, Krupp N, Paranicas CP, Kollmann P, Mitchell DG, Krimigis SM, Armstrong TP, Went DR, Dougherty MK, Jones GH (2011) J Geophys Res (Space Phys) 116:A02217. doi:10.1029/ 2010JA015954

Russell CT (2003) The Cassini-Huygens mission. Overview, objectives and Huygens instrumentarium. Kluwer Academic Publishers, Dordrecht

Sagan C (1970) Life. In: Encyclopedia Britannica. pp 964-981

Sanchez-Lavega A (2011) An introduction to planetary atmospheres. CRC Press, Boca Raton

Santos-Costa D, Blanc M, Maurice S, Bolton SJ (2003) Geophys Res Lett 30:2059. doi:10.1029/ 2003GL017972

Santos-Costa D, Bourdarie SA (2001) Planet Space Sci 49:303. doi:10.1016/S0032-0633(00)00151-3

Schubert G, Covey C, del Genio A, Elson LS, Keating G, Seiff A, Young RE, Apt J, Counselman CC, Kliore AJ, Limaye SS, Revercomb HE, Sromovsky LA, Suomi VE, Taylor F, Woo R, von Zahn U (1980) J Geophys Res 85:8007. doi:10.1029/JA085iA13p08007

Schunk RW, Nagy AF (2000) Ionospheres. Cambridge University Press, Cambridge. ISBN: 0-521-63237-4

Selesnick RS, Hudson MK, Kress BT (2013) J Geophys Res (Space Phys) 118:7532. doi:10.1002/ 2013JA019338

Selesnick RS, Stone EC (1991) J Geophys Res (Space Phys) 96:5651. doi:10.1029/90JA02696

Selesnick RS, Stone EC (1994) Geophys Res Lett 21:1579. doi:10.1029/94GL01357

Selsis F (2005) Evaporation planétaire. In: Halbwachs, JL, Egret, D, Hameury JM (eds) Ecole de Goutelas, vol XXVIII

Sharma R, Srivastava N (2012) J Space Weather Space Clim 2:A10. doi:10.1051/swsc/2012010

Sheel V, Haider SA, Withers P, Kozarev K, Jun I, Kang S, Gronoff G, Simon Wedlund C (2012) J Geophys Res (Space Phys) 117:A05312. doi:10.1029/2011JA017455

Shklovskii IS, Sagan C (1966) Intelligent life in the universe. Holden-Day, San Francisco

Shprits YY, Menietti JD, Gu X, Kim KC, Horne RB (2012) J Geophys Res (Space Phys) 117:A11216. doi:10.1029/2012JA018031

Sicard A, Bourdarie S (2004) J Geophys Res (Space Phys) 109:A02216. doi:10.1029/2003JA010203

Sicard-Piet A, Bourdarie S, Krupp N (2011) IEEE Trans Nuclear Sci 58:923. doi:10.1002/2013JA019251

Simon C, Lilensten J, Moen J, Holmes M, Ogawa Y, Oksavik K, Denig W (2007) Ann Geophys 25:661. doi:10.5194/angeo-25-661-2007

Simon C, Witasse O, Leblanc F, Gronoff G, Bertaux JL (2009) Planet Space Sci 57:1008. doi:10.1016/j. pss.2008.08.012

Slavin JA, Acuña MH, Anderson BJ, Barabash S, Benna M, Boardsen SA, Fraenz M, Gloeckler G, Gold RE, Ho GC, Korth H, Krimigis SM, McNutt RL, Raines JM, Sarantos M, Solomon SC, Zhang T, Zurbuchen TH (2009) Geophys Res Lett 36:L09106. doi:10.1029/2009GL037876

Snow M, Weber M, Machol J, Viereck R, Richard E (2014) J Space Weather Space Clim 4:A04. doi:10. $1051 /$ swsc/2014001

Stern SA (1999) Rev Geophys 37:453. doi:10.1029/1999RG900005

Svalgaard L (2013) J Space Weather Space Clim 3:A24. doi:10.1051/swsc/2013046

Svensmark H, Bondo T, Svensmark J (2009) Geophys Res Lett 36:L15101. doi:10.1029/2009GL038429

Tapping K, Valdés J (2011) Solar Phys 272:337. doi:10.1007/s11207-011-9827-1

Tian F, Kasting JF, Liu HL, Roble RG (2008) J Geophys Res (Planets) 113:E05008. doi:10.1029/ 2007JE002946

Tsagouri I, Belehaki A, Bergeot N, Cid C, Delouille V, Egorova T, Jakowski N, Kutiev I, Mikhailov A, Nyez M, Pietrella M, Potapov A, Qahwaji R, Tulunay Y, Velinov P, Viljanen A (2013) J Space Weather Space Clim 3:A17. doi:10.1051/swsc/2013037

Tsuchiya F, Misawa H, Imai K, Morioka A (2011) J Geophys Res (Space Phys) 116:A09202. doi:10.1029/ 2010JA016303

Vainio R, Valtonen E, Heber B, Malandraki OE, Papaioannou A, Klein KL, Afanasiev A, Agueda N, Aurass H, Battarbee M, Braune S, Drage W, Ganse U, Hamadache C, Heynderickx D, Huttunen-Heikinmaa K, Kiener J, Kilian P, Kopp A, Kouloumvakos A, Maisala S, Mishev A, Miteva R, Nindos A, Oittinen T, Raukunen O, Riihonen E, Rodriguez-Gason R, Saloniemi O, Sanahuja B, Scherer R, Spanier F, Tatischeff V, Tziotziou K, Usoskin IG, Vilmer N (2013) J Space Weather Space Clim 3:A12. doi:10. $1051 /$ swsc/2013030

Velinov PIY, Asenovski S, Kudela K, Lastovicka J, Mateev L, Mishev A, Tonev P (2013) J Space Weather Space Clim 3:A14. doi:10.1051/swsc/2013036 
Vennerstrom S, Menvielle M, Merayo JMG, Falkenberg TV (2012) Planet Space Sci 73:364. doi:10.1016/ j.pss.2012.08.001

Vervack RJ Jr, McClintock WE, Killen RM, Sprague AL, Anderson BJ, Burger MH, Bradley ET, Mouawad N, Solomon SC, Izenberg NR (2010) Science 329:672-675. doi:10.1126/science.1188572

Vidal-Madjar A, Désert JM, Lecavelier des Etangs A, Hébrard G, Ballester GE, Ehrenreich D, Ferlet R, McConnell JC, Mayor M, Parkinson CD (2004) Astrophys J Lett 604:L69. doi:10.1086/383347

Vieira LEA, Norton A, Dudok de Wit T, Kretzschmar M, Schmidt GA, Cheung MCM (2012) Geophys Res Lett 39(16):L16104. doi:10.1029/2012GL052950

Walt M (2005) Introduction to geomagnetically trapped radiation. Cambridge University Press, Cambridge

Wang YC, Luhmann JG, Leblanc F, Fang X, Johnson RE, Ma Y, Ip WH, Li L (2013) J Geophys Res 119: 93. doi:10.1002/2013JE004413

Watari S, Boteler D (2009) Earth Moon Planets 104:287. doi:10.1007/s11038-008-9285-4

Wedlund CS, Gronoff G, Lilensten J, Ménager H, Barthélemy M (2011) Ann Geophys 29:187. doi:10.5194/ angeo-29-187-2011

Wei Y, Fraenz M, Dubinin E, Woch J, Lühr H, Wan W, Zong QG, Zhang TL, Pu ZY, Fu SY, Barabash S, Lundin R, Dandouras I (2012) J Geophys Res (Space Phys) 117:3208. doi:10.1029/2011JA017340

West RA, Ajello JM, Stevens MH, Strobel DF, Gladstone GR, Evans JS, Bradley ET (2012) Geophys Res Lett 39:18204. doi:10.1029/2012GL053230

Wieser M, Barabash S, Futaana Y, Holmström M, Bhardwaj A, Sridharan R, Dhanya MB, Schaufelberger A, Wurz P, Asamura K (2010) Geophys Res Lett 37:5103. doi:10.1029/2009GL041721

Wilson JK, Mendillo M, Spence HE (2006) J Geophys Res 111. doi:10.1029/2005JA011364

Winglee RM, Slough J, Ziemba T, Goodson A (2000) J Geophys Res (Space Phys) 105:21067. doi:10. 1029/1999JA000334

Wood BE, Muller HR, Redfield S, Edelman E (2014) Astrophys J Lett 781:L33. doi:10.1088/2041-8205

Woodfield EE, Horne RB, Glauert SA, Menietti JD, Shprits YY (2014) J Geophys Res (Space Phys) 119:3490. doi:10.1002/2014JA019891

Woods T, Acton LW, Bailey S, Eparvier F, Garcia H, Judge D, Lean J, Mariska JT, McMullin D, Schmidtke G, Solomon SC, Tobiska WK, Warren HP, Viereck R (2004) Solar variability and its effects on climate. In: Pap JM, Fox P, Frohlich C, Hudson HS, Kuhn J, McCormack J, North G, Sprigg W, Wu ST (eds) Geophysical monograph, vol 141. Washington DC American Geophysical Union geophysical monograph series, vol 141

Zeitlin C, Cleghorn T, Cucinotta F, Saganti P, Andersen V, Lee K, Pinsky L, Atwell W, Turner R, Badhwar G (2004) Adv Space Res 33:2204. doi:10.1016/S0273-1177(03)00514-3

Zuccarello F, Balmaceda L, Cessateur G, Cremades H, Guglielmino SL, Lilensten J, Dudok de Wit T, Kretzschmar M, Lopez FM, Mierla M, Parenti S, Pomoell J, Romano P, Rodriguez L, Srivastava N, Vainio R, West M, Zuccarello FP (2013) J Space Weather Space Clim 3:A18. doi:10.1051/swsc/ 2013039 